\title{
Material Protection, Accounting and Control Technologies (MPACT) Implementation Plan: Lab-Scale Demonstration of Advanced Safeguards and Security Systems
}

August 2017

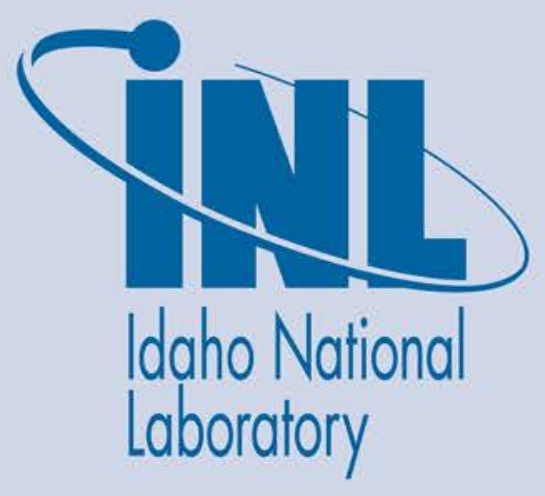

The INL is a U.S. Department of Energy National Laboratory operated by Battelle Energy Alliance 


\section{DISCLAIMER}

This information was prepared as an account of work sponsored by an agency of the U.S. Government. Neither the U.S. Government nor any agency thereof, nor any of their employees, makes any warranty, expressed or implied, or assumes any legal liability or responsibility for the accuracy, completeness, or usefulness, of any information, apparatus, product, or process disclosed, or represents that its use would not infringe privately owned rights. References herein to any specific commercial product, process, or service by trade name, trade mark, manufacturer, or otherwise, does not necessarily constitute or imply its endorsement, recommendation, or favoring by the U.S. Government or any agency thereof. The views and opinions of authors expressed herein do not necessarily state or reflect those of the U.S. Government or any agency thereof. 


\title{
Material Protection, Accounting and Control Technologies (MPACT) Implementation Plan: Lab- Scale Demonstration of Advanced Safeguards and Security Systems
}

\author{
Cipiti, B. ${ }^{1}$, Croce, M. $^{2}$, Meier, D. ${ }^{3}$, Miller, M. ${ }^{4}$, Pereira, C. ${ }^{5}$, Sanders, J. ${ }^{4}$ \\ ${ }^{1}$ Sandia National Laboratory \\ ${ }^{2}$ Los Alamos National Laboratory \\ ${ }^{3}$ Pacific Northwest National Laboratory \\ ${ }^{4}$ Idaho National Laboratory \\ ${ }^{5}$ Argonne National Laboratory
}

Idaho National Laboratory

Idaho Falls, Idaho 83415

http://www.inl.gov

Prepared for the

U.S. Department of Energy

Office of Nuclear Energy, Nuclear Technology Research and Development Under DOE Idaho Operations Office

Contract DE-AC07-05ID14517 


\section{MATERIAL PROTECTION, ACCOUNTING AND CONTROL TECHNOLOGIES (MPACT) IMPLEMENTATION PLAN: LAB-SCALE DEMONSTRATION OF ADVANCED SAFEGUARDS AND SECURITY SYSTEMS}

\section{EXECUTIVE SUMMARY}

The Materials Protection, Accounting, and Control Technologies (MPACT) campaign is working towards the goal of developing and demonstrating the next generation of nuclear materials management for the peaceful use of civilian nuclear energy. A major milestone of the campaign is the "Lab-scale demonstration of an advanced safeguards and security system," due in 2020. This implementation plan describes how tools developed in the MPACT campaign will be used to meet this milestone. These tools consist of instrumentation and devices as well as computer software for modelling, simulation and integration of data and information for safeguards and security analysis. The plan is focused on demonstrating an advanced safeguards and security systems for electrochemical processing plants, but also identifies activities needed to address advanced reactor, aqueous processing and other advanced fuel cycle facilities.

A key component to achieving the 2020 milestone is the development of a virtual distributed test bed that incorporates the instruments, data, analysis tools, and models currently under development and provides a framework to link and normalize the data in a way that simulates a facility, including uncertainty quantification. This virtual distributed test bed will integrate computer simulated facilities that make up a fuel cycle of interest, with distributed test beds located in actual operating facilities and laboratories. The MPACT campaign recently issued roadmaps for both Modelling \& Simulation and Advanced Integration which address this component, and activities necessary to achieve the 2020 milestone.

Research, development and testing of specific technologies have been supported by the MPACT campaign in coordination with other DOE-NE and NNSA programs. These technologies provide the essential data needed by the safeguards and security systems, and feed into the data analysis and facility models. This plan will identify these technologies, their current status and activities needed to demonstrate the technologies at the laboratory scale. Wherever possible, test of technologies in field conditions using suitable nuclear materials will be used to define performance. Where necessary, surrogate materials and/or simulation will be used to provide useful information for the demonstration.

When completed, the 2020 milestone will provide a demonstration of advanced safeguards and security technologies, including advanced modelling, simulation and analysis approaches, applied to electrochemical processing. It will also identify applications of the technology and approaches in other advanced fuel cycle and reactor concepts. 


\section{CONTENTS}

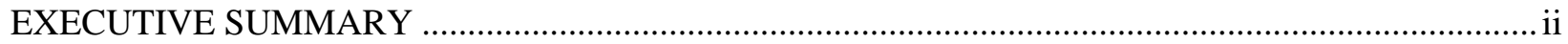

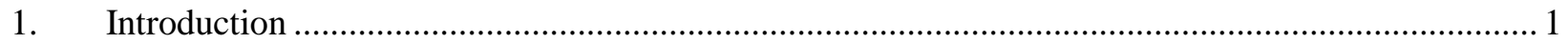

2. Advanced Safeguards and Security System Demonstration - Electrochemical Separation............... 4

2.1 Flowsheet and Unit Operation Modelling....................................................................... 4

2.1.1 Argonne Model for PYrochemical Recycling (AMPYRE) ....................................... 4

2.1.2 Dynamic Electrorefining (DyER) Simulation............................................................ 6

2.1.3 Modeling And Simulation Tool for Electrochemical Refining Systems

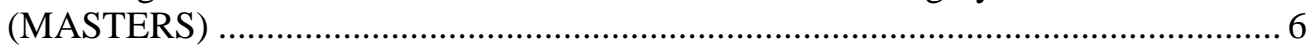

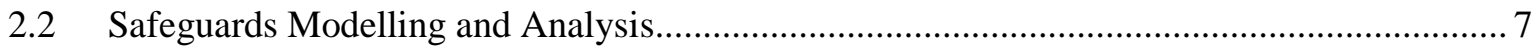

2.2.1 Separation and Safeguards Performance Model (SSPM) ....................................... 7

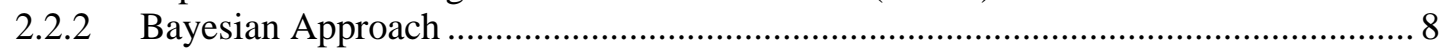

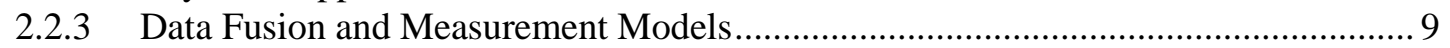

2.2.4 Process Monitoring Optimization Approach ...................................................... 9

2.3 Advanced Safeguards and Process Monitoring Technologies ............................................ 10

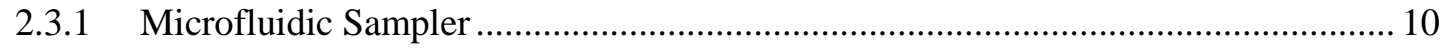

2.3.2 Electrochemical Actinide Concentration Sensor .................................................. 11

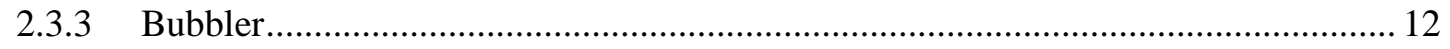

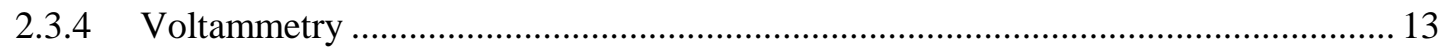

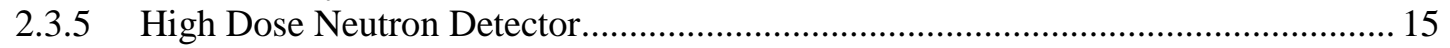

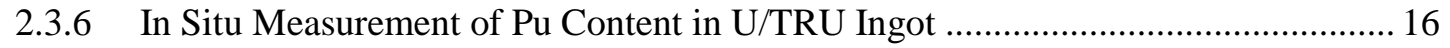

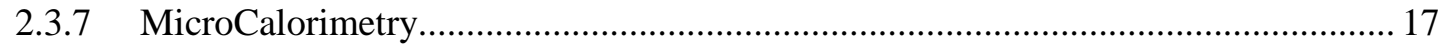

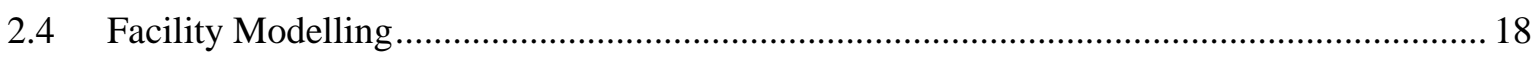

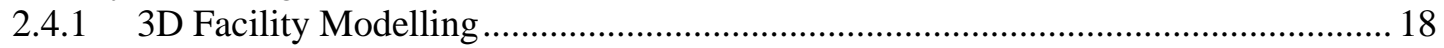

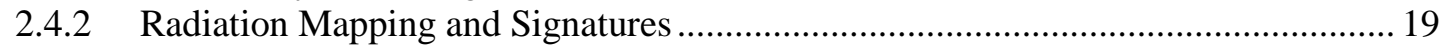



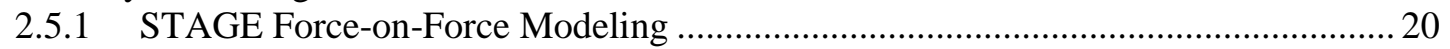



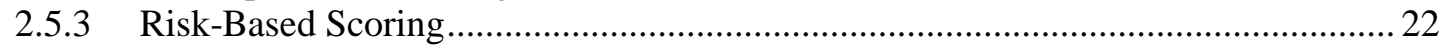

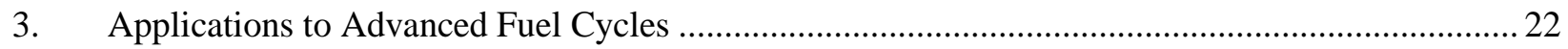

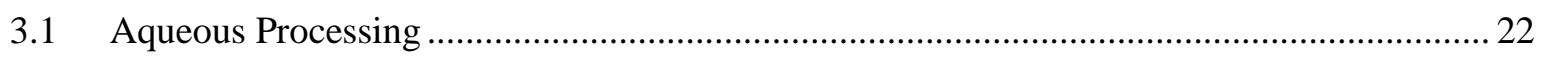

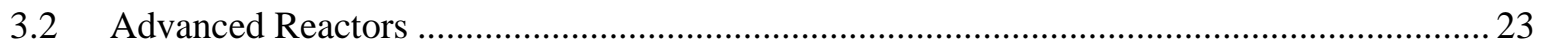

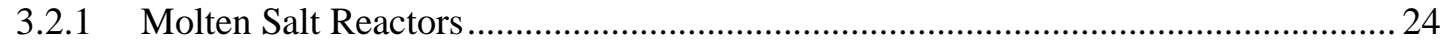

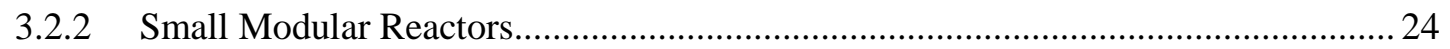

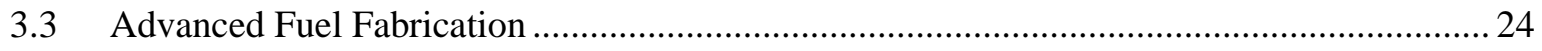

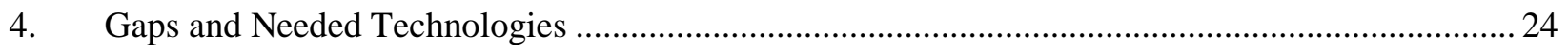

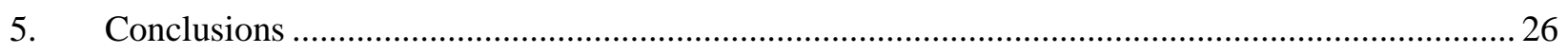

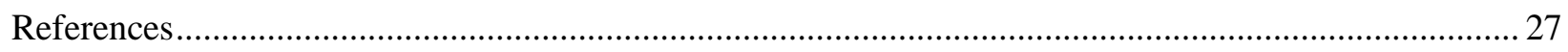




\section{FIGURES}

Figure 2. Schematic showing the major unit operations captured in AMPYRE......................................... 5

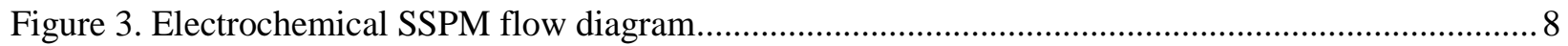

Figure 4. Pneumatic molten salt droplet generator test apparatus ......................................................... 11

Figure 5. Open circuit potential measured by the sensor as a function of time and concentration............. 12

Figure 6. Photo of the triple bubbler. (left) Schematic of the triple bubbler system. (right) ..................... 13

Figure 7. Cyclic voltammograms in $\mathrm{LiCl}+\mathrm{Li}_{2} \mathrm{O}$ on the $\mathrm{W}$ electrode. Scan rate was $200 \mathrm{mV} \mathrm{s}^{-1} \ldots \ldots \ldots \ldots . . . .14$

Figure 8. Photo of the lower portion of the OR voltammetry probe showing the electrode materials. (left) Photo of the upper portion of the probe. (right) .............................................. 14

Figure 9. High dose neutron detector external (left) and internal (right) ............................................... 16

Fig. 10. Internal and external thermocouple readings as a function of time for the solidification of

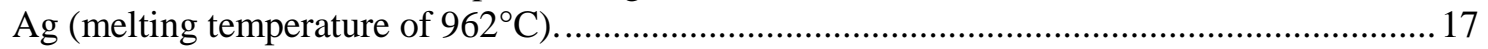

Figure 11: External view of microcalorimeter instrument................................................................... 18

Figure 12. Conceptual 3D model of a 100 MT/yr pyroprocessing facility ............................................... 19

Figure 13: Site security optimization based on the integration of multiple modeling efforts.....................20

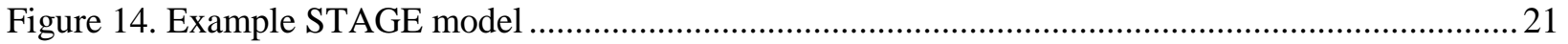

\section{TABLES}

Table 1. Identified technology gaps for advanced integration and analysis ............................................. 25

Table 2. Identified technology gaps for electrochemical processing ........................................................ 25

Table 3. Identified technology gaps for aqueous processing, advanced reactors and fuel 


\section{Introduction}

The development of sustainable advanced nuclear fuel cycles is a long-term goal of the Office of Nuclear Energy's (DOE-NE) Nuclear Technology Research and Development program. The Material Protection, Accounting, and Control Technologies (MPACT) campaign is supporting research and development (R\&D) of advanced instrumentation, analysis tools, and integration methodologies to meet this goal. This advanced R\&D is intended to facilitate safeguards and security by design of fuel cycle facilities. A major milestone of the campaign is the "Lab-scale demonstration of an advanced safeguards and security system," due in 2020. To meet this milestone, MPACT will demonstrate the use of advanced safeguards and security technologies and approaches to improve the detection of diversion, misuse, or sabotage of nuclear materials in advanced nuclear fuel cycles.

A key component to achieving the 2020 milestone is the development of a virtual distributed test bed that incorporates the instruments, data, analysis tools, and models currently under development and provides a framework to link and normalize the data in a way that simulates a facility, including uncertainty quantification. This virtual distributed test bed will integrate computer simulated facilities that make up a fuel cycle of interest, with distributed experimental test beds located in actual operating facilities and laboratories. Existing DOE owned facilities provide a variety of lab-scale test bed characteristics that can enable safeguards and Material Control and Accounting (MC\&A) research and development (R\&D) for the nuclear fuel cycle; however, none of these facilities on their own encompass the suite of capabilities needed compared to a new, advanced fuel cycle facility. Consequently, a virtual, distributed test bed can integrate these existing facilities to most efficiently represent the facility under study (for example combining process models, sensor measurements and hot cell experiments to holistically represent a reprocessing facility) or an entire fuel cycle. Model-based simulation of prototypic fuel cycle facilities will then enable targeted testing in lab-scale environments with actual or substitute signature sources.

This approach presents both a challenge and opportunity to the research community. The challenge is developing sufficient data from real instrumentation and representative process materials that one can pass results without large areas of extrapolation. Another challenge is the quantification of uncertainty at various levels, as well as aggregating and exploring correlations that may reduce overall uncertainty in the nuclear material control and accounting system.

Previous work, as described in the MPACT Advanced Integration [1] and Modeling \& Simulation Roadmaps [2], discussed the various capabilities in the MPACT program and the interdependencies. The goal of the implementation plan is to outline more specifically how these capabilities and related research will be combined to meet the 2020 milestone. The plan is focused on demonstrating advanced safeguards and security systems for electrochemical processing plants, but also identifies activities needed to address advanced reactor, aqueous processing and other fuel cycle facilities.

Research, development and testing of specific technologies have been supported by the MPACT campaign in coordination with other DOE-NE and NNSA programs for a variety of advanced fuel cycle options. These technologies provide the essential data needed by the safeguards and security systems and feed into the data analysis and facility models. This plan will identify these technologies, their current status and activities needed to demonstrate the technologies at the laboratory scale. Wherever possible, the technologies will be tested under field conditions using suitable nuclear materials. Where necessary, surrogate materials and/or simulation will be used to provide useful information for the demonstration. Additional technologies than those identified in this document will likely be investigated by the MPACT campaign, and may play an important role in achieving the 2020 milestone.

Safeguards and Security by Design (SSBD) is a methodology and discipline for integrating next generation MPACT considerations into the design of nuclear facilities from the very earliest stages. The 
MPACT Implementation Plan: Lab-Scale Demonstration of Advanced Safeguards and Security Systems

goal is to identify innovative process and facility design features that maximize the effectiveness and efficiency of safeguards and security, and to work with the design team throughout the design process to introduce such features as appropriate, minimizing the need for costly retrofits. Electrochemical processing is being used as the test case for application to advanced fuel cycle technologies, in coordination with the Material Recovery and Waste Form campaign and the Joint Fuel Cycle Study. Advanced concepts and approaches, analysis tools, and instrumentation are being developed and applied in an integrated manner to optimize the overall system effectiveness.

For purposes of this implementation plan, SSBD is tied together by four systems-level modeling capabilities. These include flowsheet modeling to set the design requirements, safeguards modeling for designing the safeguards system, 3D facility models to design the overall plant layout and timing of operations, and physical security modeling for designing the physical protection system. Linking these capabilities is the first step to achieving SSBD. During the design process, the work will be iterative so that performance metrics can be used to change the designs if needed.

The systems-level models calculate the key performance metrics, but they are fed by data gained from test beds, unit operation models, instrumentation models, statistical approaches, and research on new measurement technologies. One of the motivations of a virtual facility distributed test bed is to be able to develop safeguards and security designs without requiring full demonstration facilities, but still directing and using key test data to inform the models. The modeling ties together the work at various labs and universities.

Figure 1 shows an overview of how the capabilities all work together to achieve the virtual test bed. The four key systems modeling capabilities are shown in the middle- the performance metrics that each tool generates are shown on the right. The numerous other capabilities are labeled as "High Fidelity" because they provide much more detailed information in one area-these feed into the systems modeling capabilities. Systems level models are only as good as the data that is used to build the assumptions, so the individual instrument data, test bed data, or detailed models are key to developing an overall virtual test bed to provide useful and realistic results.

Although the flow of information on the figure is generally upward in terms of scale and to the right in terms of tangible output, the information actually proceeds in both directions as many of the capabilities and requirements are inter-related. Since the flowsheet model forms the basis of all facility operations and material flows, it is a starting point in any facility design. The safeguards model forms the basis for evaluating the effectiveness of the sensors and controls implementation within the facility. A threedimensional (3D) facility model adds dimensional constraints to the chemical and probabilistic values, and forms the basis for the deployment of security functions assessed using security modeling. Information flows downward as well. For example, the process flowsheet forms the basis for the network in the safeguards model, but assessments of timing and detection requirements impact decisions on material movement within the flowsheet. Similarly, limitations on sensor orientation due to equipment factors may necessitate rework of the safeguards valuation for a particular operation.

Proceeding from the right, the higher fidelity unit operations models are used to refine the high-level mathematical representations in the flowsheet model; as the accuracy of those representations improves, the output data is used to refine the flowsheet models. Similarly, measurement models, and statistical methods fully inform safeguards model parameters. Flow can also go leftward, as equipment layout and chemical compositions are used to generate radiation maps and direct sensor placement. The following sections describe each of the four systems level modeling capabilities, with subsections that describe the higher fidelity capabilities. 


\section{High Fidelity Capabilities Systems Level Models $\quad$ Key Metrics}
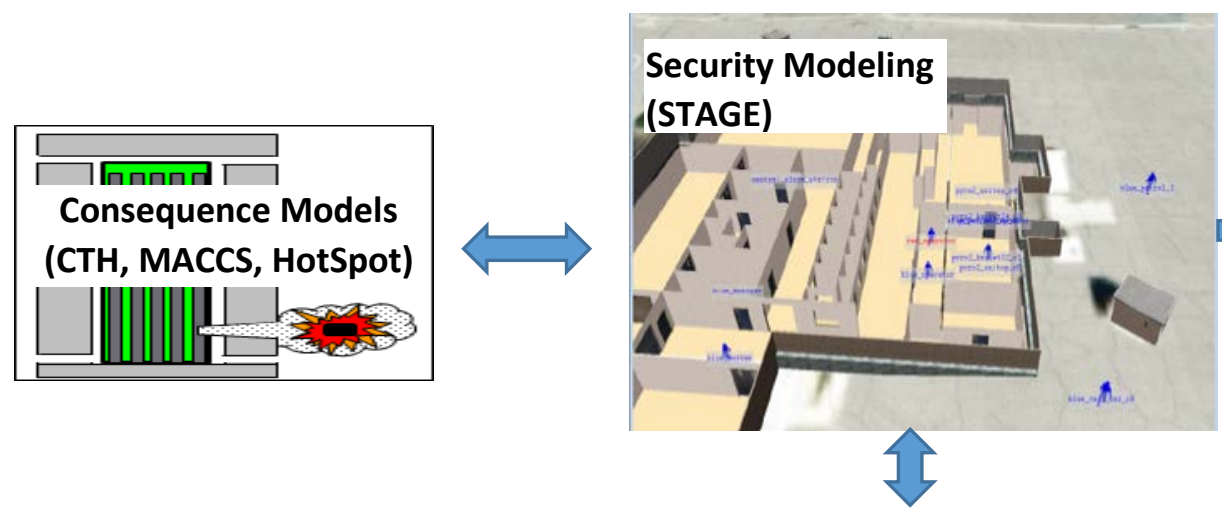

Probability of Success

Timeliness

Consequence

Radiation Signatures $\square$ (MCNP) $1:-2$
Measurement Technologies (Bubbler, Voltammetry, Microfluidic Sampler, Microcal, High Dose Neutron, Electrochemical Sensor) Measurement Models (NDA, MIP, etc.) Experimental Data (IRT, Laboratory Research)

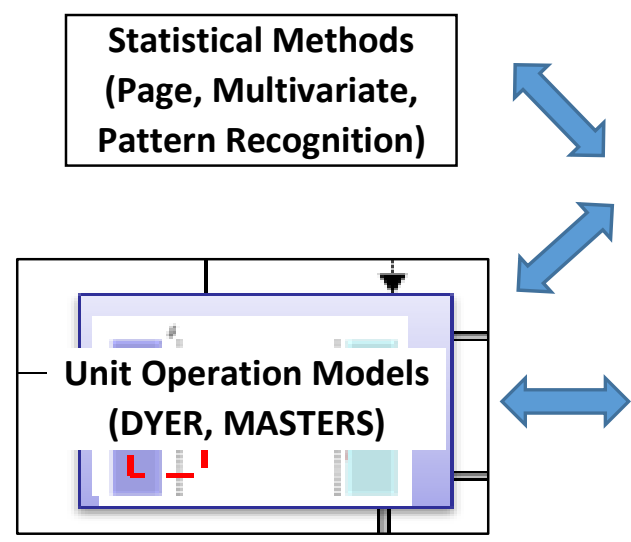

Statistical Methods Page, Multivariate
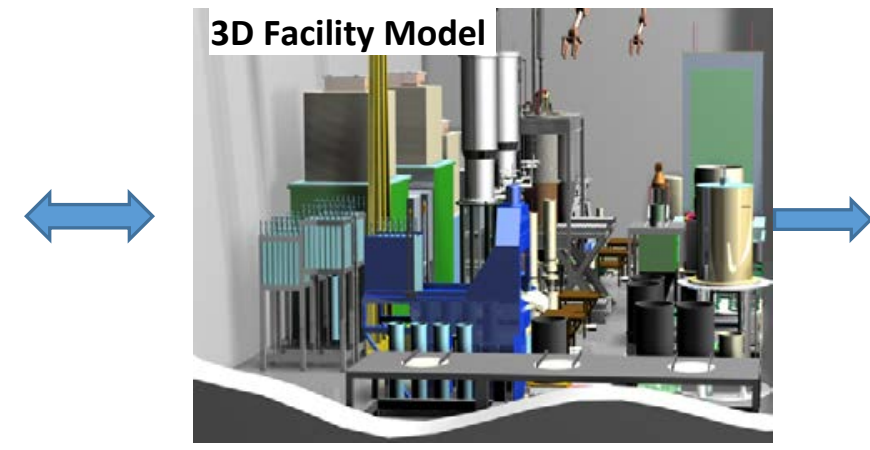

Facility Layout Batch Timing
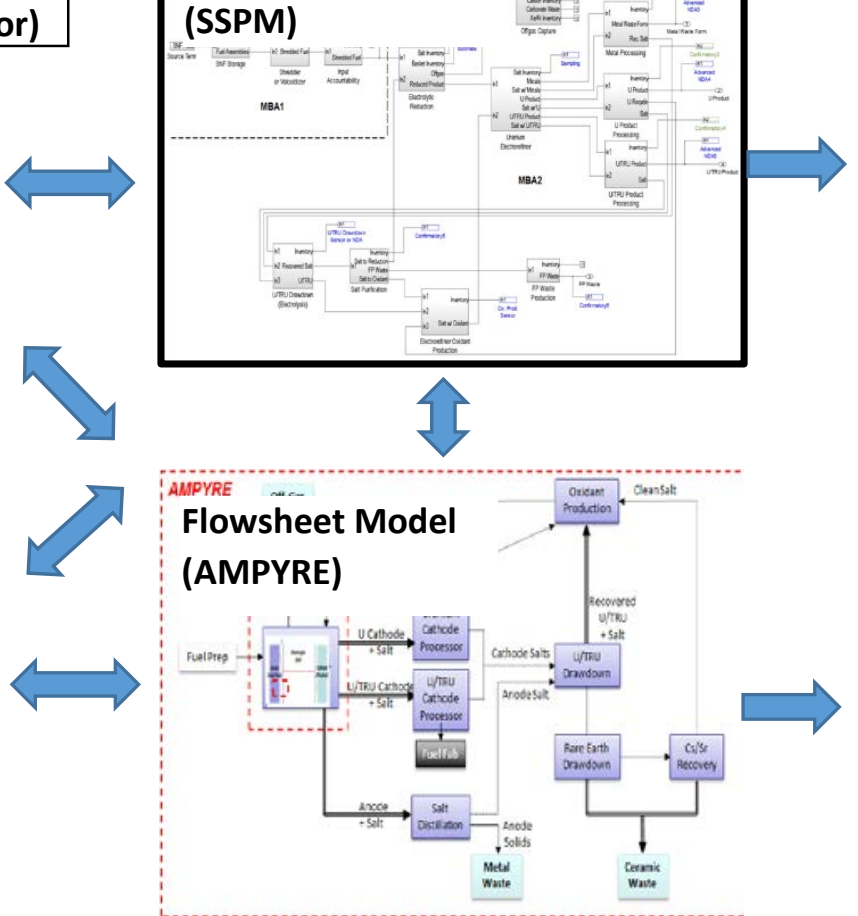

SEID (бMUF)

Probability of Detection Timeliness
Flowrates

Inventories

Separation Efficiencies

Figure 1. Virtual Facility Test Bed 


\section{Advanced Safeguards and Security System Demonstration - Electrochemical Separation}

The 2020 milestone will include an analysis of the effectiveness of advanced safeguards and security technologies applied to electrochemical processing, and comparison to traditional accountancy and security approaches. A baseline electrochemical process flowsheet will be defined that will form the basis for process, safeguards and security modelling efforts, and will be used to focus advanced integrated analysis and process monitoring (PM) approaches. Input from high fidelity electrochemical models and data from field testing of advanced quantitative instrumentation and process monitoring technologies will be integrated in the flowsheet and safeguards models to estimate flowrates, inventories, standard error of inventory difference (SEID), probability of detection and detection timeliness for the advanced safeguards system. 3D facility models and radiation signature and mapping will be developed to allow optimization of safeguards and process monitoring technologies, as well as influence facility layout and batch timing. Security consequence models will be used to perform theft and sabotage analysis for pyroprocessing. Wherever possible, field tests of advanced technologies will be performed with materials with compositions representative of the baseline flowsheet, with modelling and simulation used as needed as part of the virtual distributed test bed.

The following key milestones have been identified in order to demonstrate an advanced safeguards and security system for electrochemical processing, described in additional detail in the succeeding sections.

- Flowsheet and Unit Operation Modelling

o Determine/define flowsheet and bounding flowrates, inventories and process efficiencies

o Benchmark unit process simulations

- Safeguards Modelling and Analysis

o Determine key metrics (SEID, probability of detection, timeliness) for baseline flowsheet using traditional safeguards and security approaches using IAEA ITVs and design basis threat assessments

o Demonstrate integrated advanced analysis methodologies

o Compare safeguards key metrics to performance using advanced analysis methodologies and technologies

- Advanced Safeguards and Process Monitoring Technologies

o Field test technologies with relevant pyroprocessing materials or surrogates

- Facility Modelling

o Develop baseline 3D facility model

o Develop radiation signatures for baseline model

- Security Modelling

o Application of modelling to theft and sabotage analysis for pyroprocessing

\subsection{Flowsheet and Unit Operation Modelling}

\subsubsection{Argonne Model for PYrochemical Recycling (AMPYRE)}

Argonne National Laboratory (ANL) has developed codes for both aqueous and electrochemical reprocessing. AMPYRE is a flexible mass-balance flowsheet model for metal fuel that dynamically tracks material on a batch-by-batch basis within a pyroprocessing facility. The code captures the interdependency of unit operations including head-end processing (chopping, and oxide reduction for oxide fuel feeds), electrorefining with product collection and processing, salt recovery/treatment/recycle, and waste form fabrication. It exists in two flexible versions: Microsoft Excel®/VBA and Mathworks MATLAB ${ }^{\circledR}$, which allows for ready interfacing with DyER (section 2.1.2) and other stand-alone MATLAB-based codes. Although transient operations can be modeled as a series of process snapshots 
that demonstrate the chemical time-evolution of the facility, more recent modifications of the code now allow for sequencing of operations, independent equipment sizing, and interfacing with sensors. Expanded detail is being incorporated into each unit operation to enable independent operation of processes with variable, disparate, or conditional processing times, identification of inventory limits to turn equipment on and off, identification of material holdup between cycles, and evaluation of processing rates. AMPYRE uses thermodynamic activity data and user-defined process parameters to simulate the electrochemical and other separations that are the basis for flowsheet design. Mass balance is achieved by predicting a chemistry-based evolution of the salt, product, and waste compositions in each principle operation of the pyroprocessing flowsheet. Material is tracked by element and form while material inventories are tracked in kilograms. Currently 54 elements are tracked including fuel, salt and cladding components; over 1100 isotopes can also be tracked in the MATLAB version to evaluate the effect of varying fuel composition. Figure 2 shows the major unit operations captured with AMPYRE.

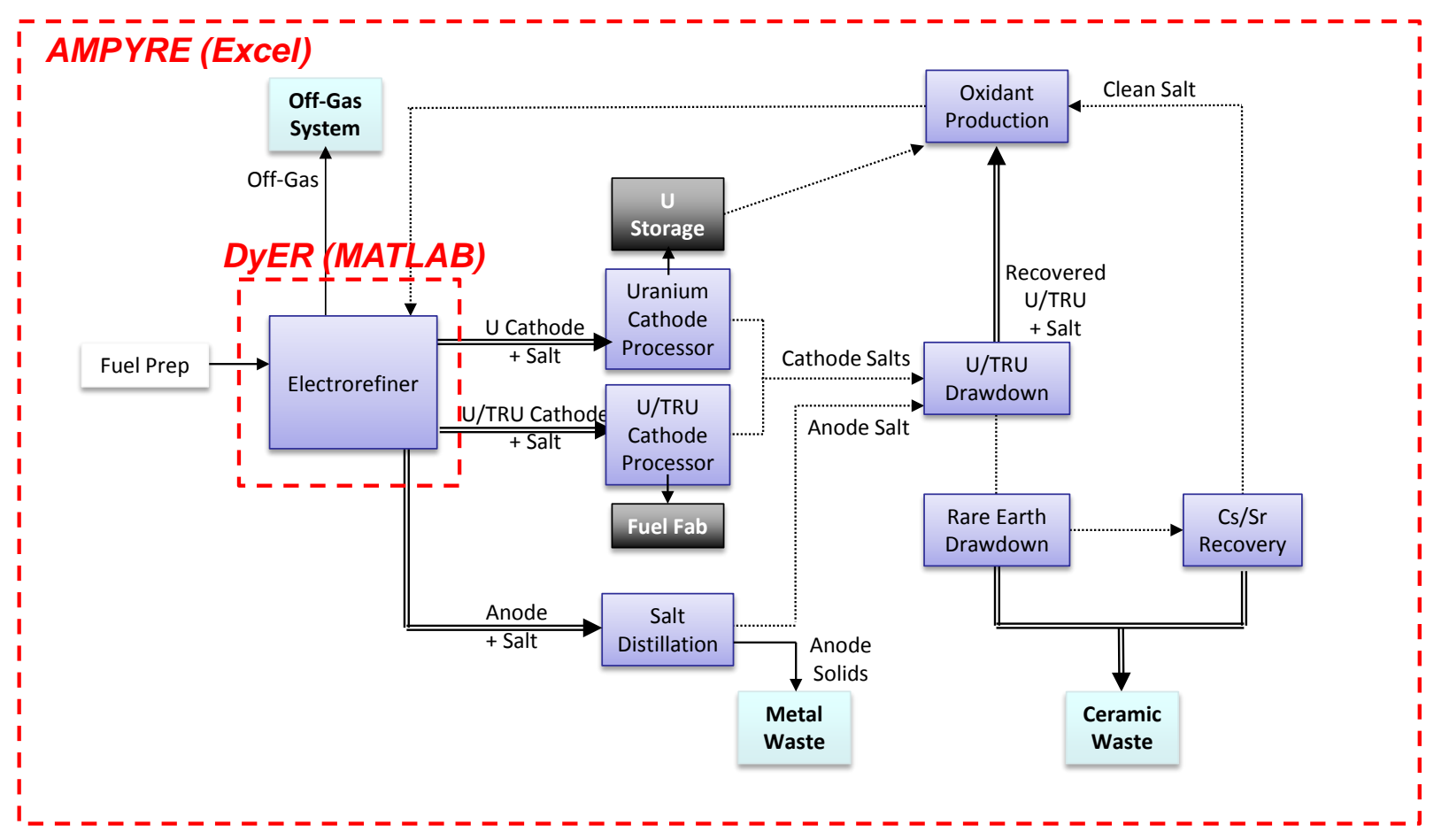

Figure 2. Schematic showing the major unit operations captured in AMPYRE.

The flowsheet forms the basis for the rest of the systems-level models, so AMPYRE serves as the natural starting point for the 2020 demonstration. As such the model can serve as a linkage tool for the virtual test bed through generation of composition datasets to serve as inputs for other codes, sensor evaluation studies, and experiment designs. As a feedback, data from sensors and specialized measurement techniques can serve as inputs to evaluate the measured and calculated response for a defined set of process conditions. Because of the multi-level nature of the virtual test bed scheme outline in Figure 1, a key goal will be to better integrate AMPYRE with the SSPM code (section 2.2), to continue to integrate the DyER code and other unit operations model under development, and to benchmark the model results with the MASTERS code (section 2.1.3).

AMPYRE provides much more detail on the chemistry modeling, especially with the integration of DyER. The results can be used to generate empirical relations to improve the fidelity of the safeguards model. Of particular interest would be an empirical relation for the extraction rate of U and U/TRU onto 
MPACT Implementation Plan: Lab-Scale Demonstration of Advanced Safeguards and Security Systems

the various cathodes as a function of concentrations in the salt assuming a fixed current and voltage. This empirical relation could be worked into the SSPM without requiring a full integration of codes.

To support the 2020 milestone, the AMPYRE will be used to model the baseline flowsheet. The AMPYRE and DyER codes have some overlap with the MASTERS code, but the two capabilities should be benchmarked against one another. This could strengthen both modeling capabilities by finding and resolving differences.

\subsubsection{Dynamic Electrorefining (DyER) Simulation}

DyER (Dynamic Electrorefining) simulates the movement of material among the anode, cathode, and salt within an electrorefiner as spent fuel is processed into metallic products for recycle or storage. DyER employs chemical expressions derived from fundamental kinetics and thermodynamics for electrochemical processes, and system-specific chemical data developed at ANL, to produce timedependent simulations of the electrorefiner operation. Model parameters include batch size, current or voltage control, electrode type, dual cathode operation, and salt composition ( $\mathrm{LiCl}-\mathrm{KCl}$ or $\mathrm{LiCl}$ ). The model output can be used to predict the changes in transient behavior due to changes in operations or input compositions. The code output can be interfaced directly with AMPYRE to provide a more rigorous simulation of the composition of the products generated in the electrorefiner for a set of user-defined operation conditions, and the overall mass balance in the facility. The code is written in MATLAB, and input parameters can be input directly by the user or imported directly from Excel spreadsheets.

DyER can also be used to generate simulated current and voltage data which would be useful for process monitoring. Process monitoring may play a key role in pyroprocessing safeguards, but related work in MPACT requires example data to develop pattern recognition or other statistical approaches. DyER can help provide simulation data for both normal and off-normal operations. This should significantly improve the statistical and data fusion approach over the next two years.

In addition to DyER, electrochemical process models were developed for the salt treatment steps of actinide recovery and lanthanide drawdown, as well as the oxide reduction process when the feed is an oxide fuel. These codes are also written in MATLAB and use a mathematical approach similar to DyER. Development of higher fidelity unit operations models for the salt distillation, oxidant production, and cathode product processing would further augment the models currently included in AMPYRE.

\subsubsection{Modeling And Simulation Tool for Electrochemical Refining Systems (MASTERS)}

Idaho National Laboratory (INL) has developed, with support from the DOE-NE Material Recovery and Waste Form Development Campaign, a pyroprocessing batch model used extensively for planning purposes for various missions including the EBR-II processing and Joint Fuel Cycle Study (JFCS). Recently, the software system was named as MASTERS (Modeling And Simulation Tool for Electrochemical Refining Systems). The model implemented in the simulation software uses the reported thermodynamic separation factor in an effort to eliminate the dependency on the domain expert inputs for tracking the actinides and the lanthanides. The simulation software heavily relies on the domain expert inputs provided via the user interface where experiences matter the most than idealistic thermodynamic calculations, such as, the bond sodium and the off-gas partitions. Also implemented are the selected operational constraints coming from the physical cell size and the criticality related constraints induced by the fissile materials, which are adjustable. This feature allows the user to assess the impact of its physical cell design and criticality consideration to the performance of the flowsheet. The correctness of the developed simulation software is partly established through the mass balance check of the inventory. 
A molten salt electrochemistry is the heart of electrochemical spent fuel processing concept. The active metal fission products including alkali metal, alkali earth metals, transuranics, and lanthanides become chlorides and report to the electrolyte. The metallic species more stable than uranium such as zirconium and iron remain in the anode as metals. MASTERS electrorefining process sub-model gives the material partition among electrolyte, anode, and cathode as a fuel batch is processed. The change of electrolyte compositions in the electrorefiner unit is tracked as the batches of fuels are processed. Besides the material partition model based on the molten salt electrochemistry, MASTERS consider operational constraints for the operation of the electrorefiner.

The MASTERS model is the framework for the pyroprocessing PM assessment described in section 2.2.4, and a framework already exists to import relevant data. MASTERS also exists as a stand-alone simulation file that can be run with variable parameters. Future work is needed to benchmark MASTERS to AMPEYER and DYER models, with refinement and specialization as needed. Based on this benchmarking and comparison, MASTERS may be used to model portions of the baseline flowsheet to support the 2020 milestone.

\subsection{Safeguards Modelling and Analysis}

\subsubsection{Separation and Safeguards Performance Model (SSPM)}

The safeguards modeling capability is contained within the Separation and Safeguards Performance Model (SSPM). The SSPM is a transient MATLAB Simulink model that tracks elemental and bulk material flow through a reprocessing plant for safeguards design and analysis. Various versions of the model exist for aqueous (PUREX and UREX+), electrochemical reprocessing, and enrichment. The base of the model simulates unit operations including separation of materials and process vessel inventories. Both bulk and materials accountancy measurements are simulated throughout the plant with user-defined measurement uncertainties. These measurements are used to calculate an inventory difference over a specific material balance period as the model runs. Statistical tests are used to set alarm conditions for detecting material loss.

Figure 3 shows an electrochemical version of the SSPM in Simulink. The gray blocks represent the unit operations, and the signals connecting them contain the mass flow information. Significant detail is included in each of the unit operation blocks to control vessel filling and emptying, separation fractions, timing sequences, and control switches. Elements 1-99 are tracked along with the bulk materials (salt in the case of pyroprocessing). Chemistry is not modeled unless it has been integrated from another code.

The blue blocks represent accountancy measurements that may be taken throughout the plant. The simulated measurements are fed into a monitoring subsystem that contains all the calculations necessary for the Inventory Difference (ID), Standard Error of the Inventory Difference (SEID), and statistical tests for setting alarms. The SSPM also contains the ability to model diversion scenarios to examine how the safeguards system will respond. Recent work has examined more use of process monitoring data with the overall safeguards balance.

One of the on-going tasks related to the SSPM is to update the model as data from experimental tests and new measurement technology becomes available. This may include updating separation fractions in the base of the model or assumptions for uncertainties in specific measurement technologies. Future work will need to document these assumptions. 
Another key integration task will be to incorporate activities related to process monitoring statistics. A current NEUP project is developing advanced data fusion techniques for integrating process monitoring information as well as developing NDA models to directly integrate in the SSPM. As part of the NEUP, SSPM has already been modified to better integrate these capabilities. More work will be needed to integrate the Bayesian as well as the process monitoring approaches being investigated.

Finally, where practical, the SSPM can improve model fidelity by integrating unit operation models. An empirical relation for the electrorefiner extractions (as described earlier) would be beneficial. Capabilities from the MASTERS code could also be considered for other unit operations.

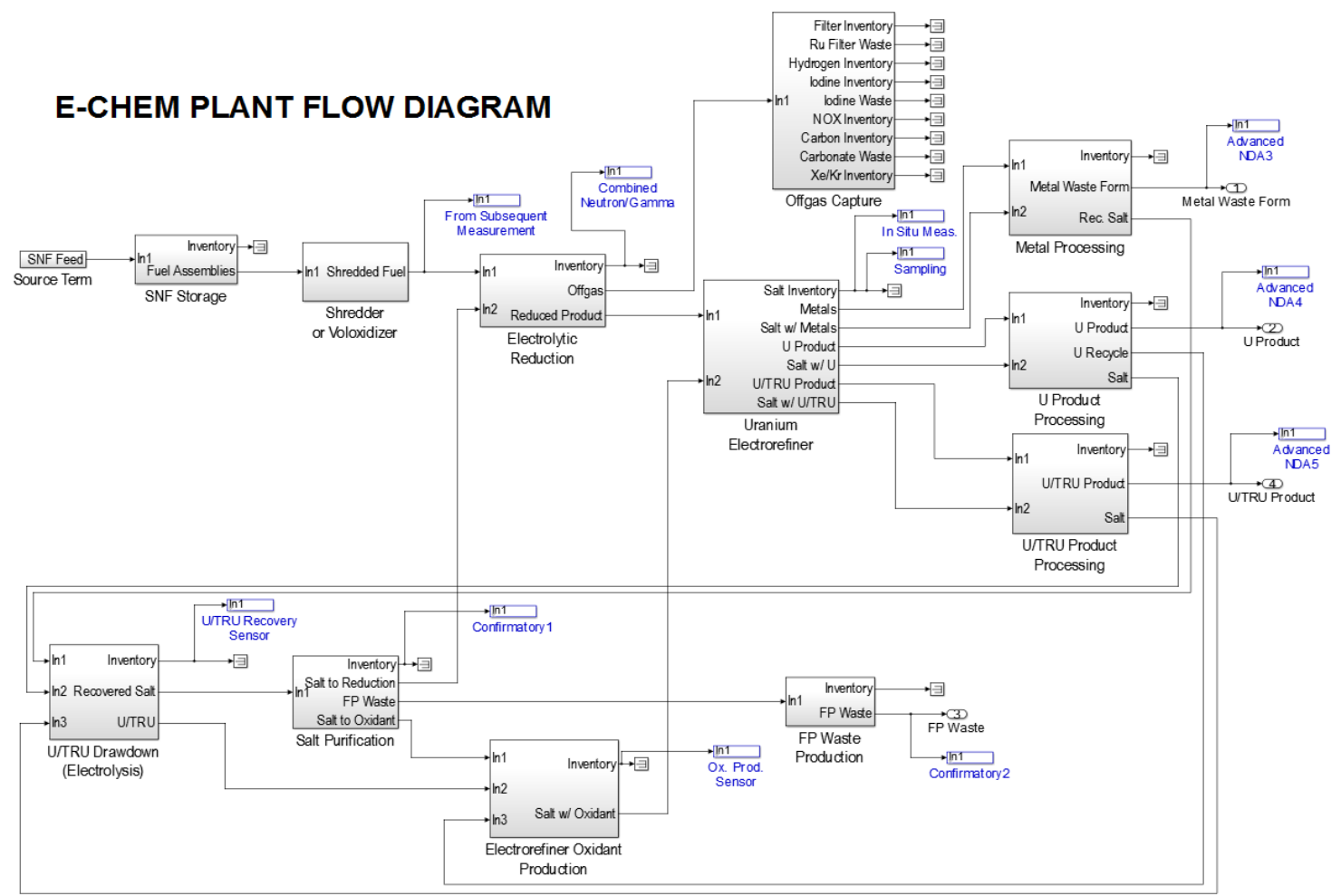

Figure 3. Electrochemical SSPM flow diagram

All of these tasks will help to contribute to improve the results for the key safeguards metrics. Increased model fidelity improves confidence in the results and helps with investigating the integration of traditional MC\&A data with process monitoring approaches. Improved assumptions for the process and measurement technology will improve the quality of the results.

\subsubsection{Bayesian Approach}

The problem of integrating disparate data, commonly termed data fusion, can be approached probabilistically using Bayesian statistical analysis. To review this concept briefly, subjective estimates of the Poisson parameter called prior distributions are "updated" using available operating data to produce an updated estimate of the parameter. When there is little operating data or useful surrogate data, the prior distribution can dominate the results. Such prior distributions often are generated using expert judgement, which is difficult to document, and the original justification for the data may be lost. 
MPACT Implementation Plan: Lab-Scale Demonstration of Advanced Safeguards and Security Systems

In this fusion approach for the data, Bayesian methods are used to include non-statistical knowledge about the vulnerability of a facility to a diversion of nuclear material. An important innovation is the use of the mathematical tools of evidential reasoning to capture the knowledge base and reasoning used by experts in constructing prior distributions. This approach provides a rigorous, reproducible, and traceable basis for the prior distribution. It also provides a means for explicitly indicating uncertainty about the prior distribution using confidence and non-specificity as an uncertainty measure; however, these calculations are not performed for this report. In a typical Bayesian analysis, the uncertainty about the prior distribution is folded into the distribution itself, a practice that tends to obscure the issues involved in generating the prior distribution. In this advanced integration method, this source of uncertainty is treated separately and differently from probabilistic uncertainty.

Future work will examine how the Bayesian approach can be integrated with existing modeling tools, including both the safeguards and security models. The approach will be compared to other approaches for integrating disparate data.

\subsubsection{Data Fusion and Measurement Models}

A NEUP project is examining improved data fusion algorithms to improve safeguards modeling and the integration of process monitoring data, specifically for pyroprocessing. This project is in partnership with Sandia National Laboratories to integrate the capability into the SSPM.

The first group of tasks includes developing models for NDA and process monitoring measurements that will be incorporated into the SSPM. This required expanding the SSPM capabilities to include full isotopic tracking and making data outputs more standardized. The goal is to be able to simulate NDA measurements based on the material flows in the model.

The second group of tasks include developing data fusion algorithms that combine nuclear material accountancy measurements with process monitoring and other NDA measurements for drawing safeguards conclusions. These approaches may include multivariate analyses and pattern recognition techniques applied to current and voltage monitoring or voltammetry measurements for the key unit operations in pyroprocessing. The final objective is to test the approaches using simulation for both normal and off-normal scenarios. The goal is to develop methods that are robust to varying plant conditions.

The tasks within the NEUP are aligned well with the 2020 milestone. Where possible, process monitoring aspects would benefit from facility or experimental data. This will be made available through the tests at INL and through modeling work at INL and ANL, as appropriate.

\subsubsection{Process Monitoring Optimization Approach}

An advanced safeguards approach and associated methods for process monitoring has been applied by INL to a hypothetical nuclear material processing system. The assessment regarding the state of the processing facility is conducted at a system-centric level formulated in a hybrid framework. This utilizes architecture for integrating both time- and event-driven data and analysis for decision making. While the time-driven layers of the proposed architecture encompass more traditional process monitoring methods based on time series data and analysis, the event-driven layers encompass operation monitoring methods based on discrete event data and analysis. By integrating process- and operation-related information and methodologies within a unified framework, the task of anomaly detection is greatly improved. This is because decision-making can benefit from not only known time-series relationships among measured signals but also from known event sequence relationships among generated events. This available 
MPACT Implementation Plan: Lab-Scale Demonstration of Advanced Safeguards and Security Systems

knowledge at both time series and discrete event layers can then be effectively used to synthesize observation solutions that optimally balance sensor and data processing requirements. The application of the proposed approach has been implemented on an illustrative monitored system based on pyroprocessing.

In support of the 2020 milestone, application of this approach using commonly available PM technologies will be analyzed, as well as performance with advanced PM technologies. Optimization of placement and use of advanced PM technologies, as well as identification of potential key technologies will be also performed.

\subsection{Advanced Safeguards and Process Monitoring Technologies}

\subsubsection{Microfluidic Sampler}

Tracking the composition of salt as it moves through an electrochemical reprocessing facility is a difficult task because electrochemical material processing is done continuously at elevated temperatures, while transfers involve discrete batches of used fuel or solids with adhered salts. Salt is recycled at several points within the process, making it difficult to relate changes in composition to specific processing operations. Particularly over long time steps, small differences or inhomogeneities may result in quantifiable changes in product output compositions. It is desirable to obtain an accurate and timely measure of the chemical and isotopic composition of the salt within the electrorefiner and through other operations in the facility to fully close the material mass balance.

To meet these goals, the system under development uses automated high-throughput micro-sample generation and at-line analysis to combine the best aspects of destructive analysis (high sensitivity, low measurement uncertainty, and high quantitative resolution) with the best aspects of non-destructive analysis (low sample loss, low processing impact, and rapid turnaround). A product of this work has been the development of a pneumatic apparatus for generating molten salt samples with sizes ranging from a few hundred nanoliters to several hundred microliters. Due to its ability to produce a large range of sample sizes, this apparatus has utility both for experimental work and for the generation of pyroprocess samples for off-line analysis. The system was originally intended to be operated as a continuously circulating sampling system, but has been found to operate successfully in batch mode.

High throughput micro-sample generation and analysis of UCl3-LiCl-KCl salts has been carried out with a prototype system. X-ray fluorescence (XRF) spectroscopic studies demonstrated that, despite the wide distribution of individual measurements, highly linear calibration curves could be generated for the 3 largest uranium XRF peaks by normalizing to the $\mathrm{Cl}$ peak height, and by averaging the results of 105 droplet analyses per $\mathrm{U}$ concentration. This effect is the result of the averaging out of random measurement errors. Uranium XRF spectra were also compared to existing fission product surrogate salt micro-sample spectra and literature values for other potential electrorefiner salt components to demonstrate that the fission product XRF peaks will not interfere with the U and Pu XRF spectra. 

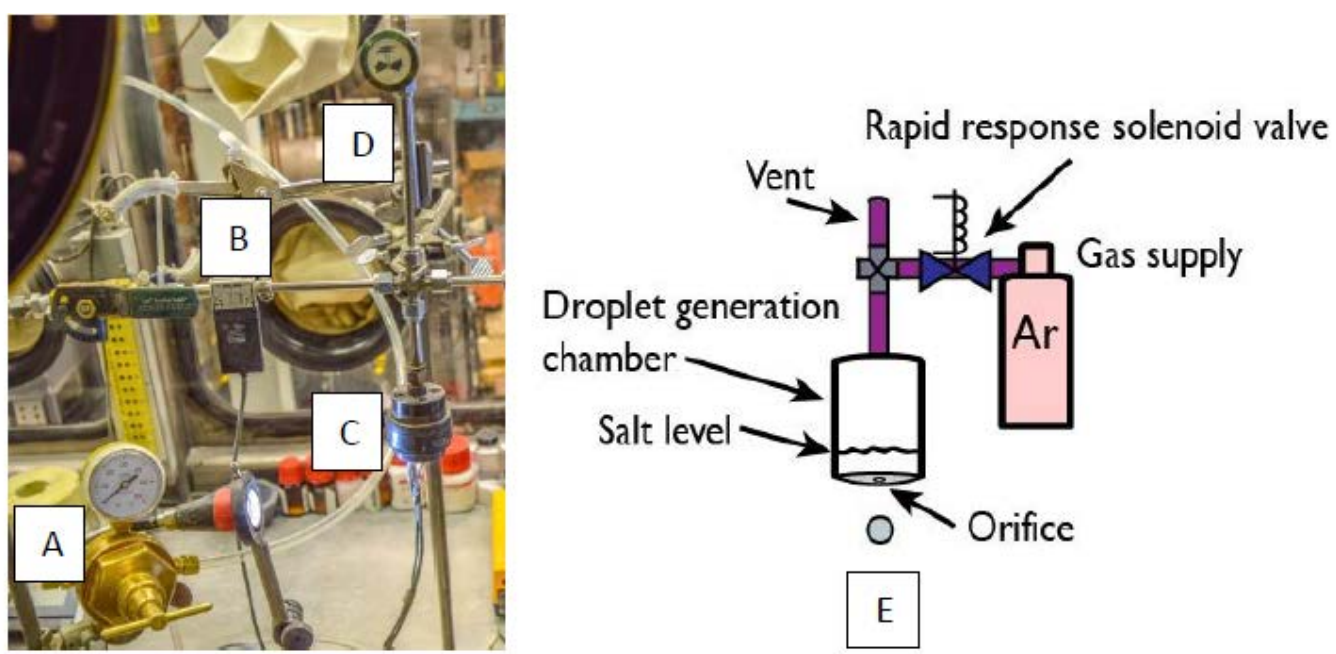

Figure 4. Pneumatic molten salt droplet generator test apparatus (A) Line regulator (B) Rapid response solenoid valve (C) Molten salt reservoir chamber with band heater (D) Gas vent with metering valve (E) Schematic of pneumatic molten salt droplet generator apparatus showing salt level, orifice, and salt droplet

For the 2020 milestone, tests with a variety of salt compositions, including spent nuclear fuel is ideally needed to augment the existing set of surrogate data, as well as testing of possible measurement approaches to minimize uncertainty and systematic effects.

\subsubsection{Electrochemical Actinide Concentration Sensor}

A solid-state electrochemical sensor is being developed to provide a reliable and cost-effective real-time in-situ monitoring technology for prompt determination of actinide concentrations in a molten salt during treatment of used nuclear fuel. The technology is highly desired for maintaining process efficiency and to prevent attempt of producing plutonium rich metal products during electrorefining operations. The objective of the work is to develop a sensor that is selective and stable while providing a sufficient degree of sensitivity to variation of actinide concentrations in the molten salt used for electrorefining operations in order to improve online process monitoring capabilities.

The sensor is comprised of a metallic electrode immersed in a reference salt contained within a ceramic membrane (Beta-Alumina) that has been pre-loaded via ion exchange with the element to be selectively measured. The sensor is lowered into the salt and operated with respect to pseudo Pt or Ag/AgCl reference electrode. With this configuration, the sensor measures the open circuit potential (OCP) which changes as a function of the concentration of the selected element in the salt.

In the initial stages of the work, $\mathrm{Gd}^{3+}$ was used as a surrogate for $\mathrm{Pu}^{3+}$. In this phase, the $\mathrm{Na}^{+}-\beta^{\prime}-\mathrm{Al}_{2} \mathrm{O}_{3}$ ceramic membrane material was immersed in $\mathrm{GdCl}_{3}$ where the $\mathrm{Gd}^{3+}$ ion exchanged with the $\mathrm{Na}^{+}$. Operating this material with respect to a Pt wire in $5 \mathrm{wt} \% \mathrm{GdCl}_{3}-\mathrm{LiCl}-\mathrm{KCl}$ reference salt with respect to a pseudo Pt reference electrode yielded promising results. Figure 5 shows a plot of the measured OCP as a function $\mathrm{GdCl}_{3}$ insertion into the bulk salt. 


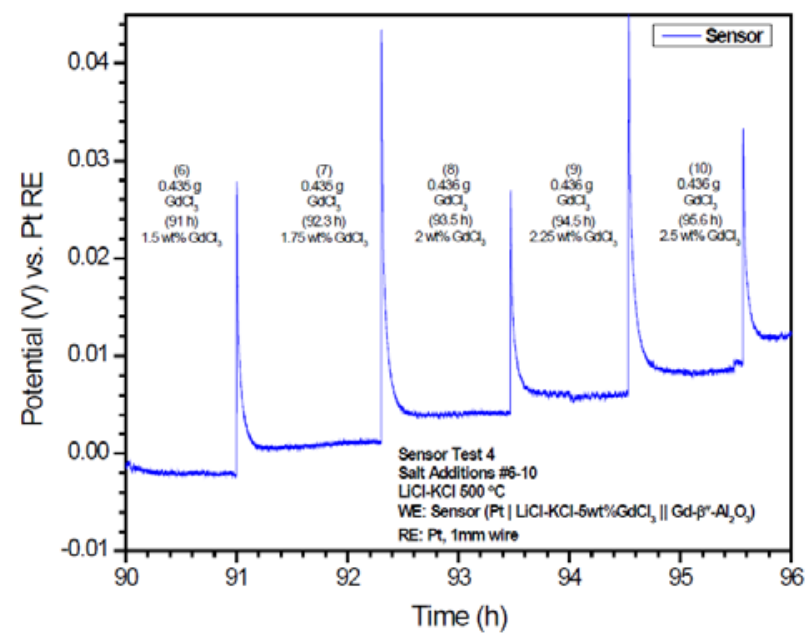

Figure 5. Open circuit potential measured by the sensor as a function of time and concentration.

Following the successful Gd probe design, work has focused on creating a sensor that is sensitive to U. Currently, an ion exchange beta alumina has partially been achieved and tested using a Cd-Gd metal electrode in the sensor. Preliminary testing of the probe shows that this technology has great potential as an actinide sensor to measure special nuclear materials in the ER in-situ and in real-time.

To support the 2020 milestone, tests of the sensor to measure uranium and plutonium in salts representing the complexity seen from electrorefining of spent nuclear fuel are needed to augment lower fidelity benchmark data.

\subsubsection{Bubbler}

In addition to monitoring the concentration of nuclear materials in the ER, it is important to measure the density and volume of the salt in order to determine the mass of each component in the vessel. A bubbler probe is under development at INL to directly measure the salt density, surface tension, and depth in molten salt tanks. Tank measurements to quantify the fluid depth in a tank are established in ISO standards using a double bubbler system. Preliminary work in molten salts showed that the addition of a third bubbler tube was necessary to overcome surface tension effects

The triple bubbler system is shown in Figure 6. The two lower bubbler tubes $\left(r_{2}\right.$ and $\left.r_{3}\right)$ are positioned at the same depth and are used to determine the surface tension. The third tube $\left(\mathrm{r}_{1}\right)$ is placed $10 \mathrm{~cm}$ above the others and is used for density and depth measurements. 

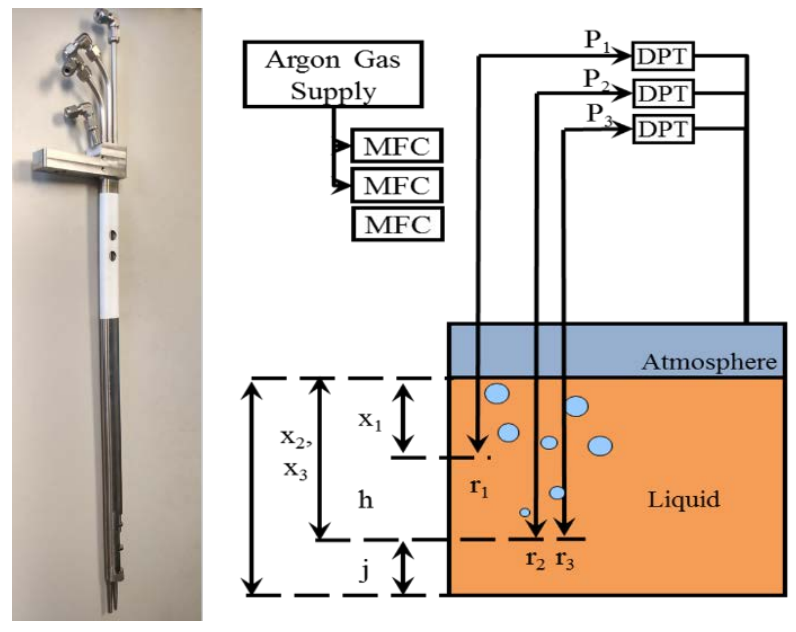

Figure 6. Photo of the triple bubbler. (left) Schematic of the triple bubbler system. (right)

The density and surface tension of the fluid is related to the measured pressure through the YoungLaplace equation. However, due to the surface tension effects, a straightforward solution was not possible without experimentally determining (calibration) correction factors for density and the surface tension for the given system. With the correction factors determined, the density and surface tension of the fluid can be accurately determined.

The triple bubbler system was tested in molten $\mathrm{LiCl}-\mathrm{KCl}$ salt between $425^{\circ} \mathrm{C}$ and $525^{\circ} \mathrm{C}$ in a glove-box. The system calibration yielded a density coefficient and surface tension coefficient that were relatively constant with temperature. The agreement between the measured and expected values was quite good with the \% difference being less than $0.1 \%$. In laboratory conditions, the depth of the salt was measured independently using a dipstick method. At $500^{\circ} \mathrm{C}$, the salt depth via the dipstick method was measured to be $6.125 \pm 0.1 \mathrm{~cm}$ with the depth determined by the bubbler $5.96 \pm 0.003 \mathrm{~cm}$. Though the results agree within limits of standard error, experiments are ongoing to get an improved independent salt measurement for the comparison, and realistic uncertainty estimate for the bubbler measurement using a variety of furnaces to closely simulate hot-cell operation.

The bubbler probe was installed in the JFCS electrorefiner, but removed during a redesign. A secondary bubbler is being calibrated and is planned to be installed for field testing. To support the 2020 milestone, the bubbler could be modified for use in the oxide reduction furnace with the focus of online detection of changes in density and depth consistent with operations as a process monitoring tool.

\subsubsection{Voltammetry}

\subsubsection{Oxide Reduction Voltammetry}

Following the SNF declading process, the fuel is loaded into the oxide reduction (OR) system to reduce the $\mathrm{UO}_{2}$ fuel into a metallic form suitable for electrochemical separation in the electrorefiner. The crushed $\mathrm{UO}_{2}$ fuel is loaded into a cathode basket and immersed into a molten $\mathrm{LiCl}$ electrolyte salt with $1 \mathrm{wt} \%$ $\mathrm{Li}_{2} \mathrm{O}$ at $650^{\circ} \mathrm{C}$. Under normal operating conditions, the rare earth fission products and actinides in the fuel will not form soluble chlorides in the salt. To ensure normal operation, a novel OR voltammetry probe is currently under development at INL that utilizes tungsten (W) or tantalum (Ta) working electrodes that can be used to monitor the OR. 
Laboratory scale experiments are being conducted within a glovebox at the Center for Advanced Energy Studies (CAES) to perform cyclic voltammetry (CV) and electrochemical impedance spectroscopy (EIS) measurements. Figure 7 shows the CV measurements with $\mathrm{W}$ as the working electrode. With each addition of $\mathrm{Li}_{2} \mathrm{O}$ into the system the CV plots change. The same is true for the EIS measurements. Analysis of the results are ongoing but it appears that the $\mathrm{Li}_{2} \mathrm{O}$ concentration in the OR salt can be determined quantitatively using CV and/or EIS measurements.

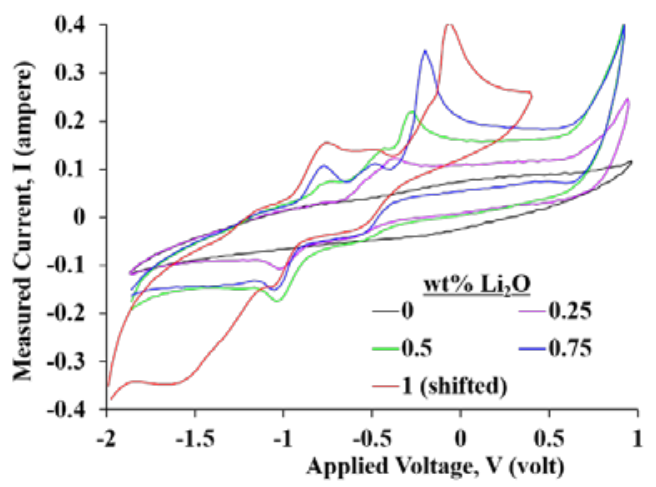

Figure 7. Cyclic voltammograms in $\mathrm{LiCl}+\mathrm{Li}_{2} \mathrm{O}$ on the $\mathrm{W}$ electrode. Scan rate was $200 \mathrm{mV} \mathrm{s}^{-1}$.

Concurrently with the laboratory scale experiments, an engineering scale voltammetry probe has been constructed and tested in the INL Engineering Development Laboratory (EDL). The voltammetry probe is shown in figure 8. The probe consists of a long $\mathrm{MgO}$ tube supporting $\mathrm{W}$ and Ta working electrodes and two $\mathrm{Ni} / \mathrm{NiO}$ reference electrodes. The probe was designed to be used in a hot cell environment where access is limited to mechanical manipulators.

Tests and analysis are ongoing to better understand the electrode material selection and the electrochemical response with respect to the $\mathrm{Li}_{2} \mathrm{O}$ concentration. However, preliminary experiments conducted at CAES and at EDL have demonstrated that the CV and EIS electrochemical measurements have the capability to measure the $\mathrm{Li}_{2} \mathrm{O}$ concentrations in the OR system. The voltammetry probe under development at INL can monitor the OR salt in order to ensure the system is operating under normal conditions and to verify that the equipment is not being misused. This sensor will be an important tool for process monitoring and safeguards of the OR process used in pyroprocessing.

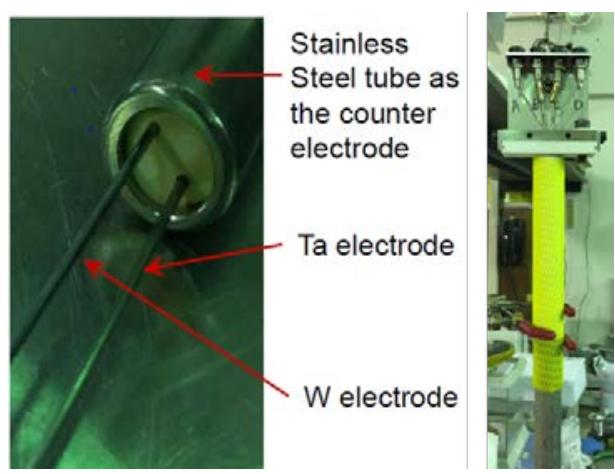

Figure 8. Photo of the lower portion of the OR voltammetry probe showing the electrode materials. (left) Photo of the upper portion of the probe. (right) 
MPACT Implementation Plan: Lab-Scale Demonstration of Advanced Safeguards and Security Systems

\subsubsection{Electrorefiner Voltammetry}

The molten salt solutions used in these fuel-processing scenarios are very challenging as they include high concentrations of multiple electrochemically active species, thereby creating a variety of complications. Some of the problems that arise therein include issues related to uncompensated resistance, cylindrical diffusion, and alloying of the electrodeposited metals. These phenomena alter the current response to the applied potential waveform, leading to erroneous electroanalytical predictions. Improvements to the existing voltammetry technique to account for all of these issues have been implemented, resulting in good measurements of actinide concentrations across a wide range of conditions.

For single-component salts, the improved analytical approach has been shown to account for the peak broadening and attenuation of peak currents that occurs as concentrations of the actinide species are increased. In doing so, accurate electroanalytical predictions have been shown to be possible across the full range of expected actinide concentrations in fuel processing equipment. For multicomponent salts, the improved analytical approach has been shown to account for alterations to the current response that arise due to alloying effects in co-deposited metals. At present, the fitting of digital simulations to experimental cyclic voltammograms is a manually performed task that is somewhat time-consuming, but automation of the procedure could be readily developed.

A robust voltammetric sensor module has been designed and constructed, and preliminary experimental tests have shown that the sensor behaves as anticipated. Issues such as multiplexing and cross-talk were examined. The development of this improved methodology along with the sensor module will allow for fast, timely electroanalytical measurement of actinide concentrations in molten salts, thereby providing materials protection and accountancy necessary for real-world fuel processing equipment.

To support the 2020 milestone, the sensor will need to be tested in electrorefining salts with a variety of compositions, ideally to include spent nuclear fuel.

\subsubsection{High Dose Neutron Detector}

Electrochemical processing will result in products and equipment with extremely high gamma-ray dose levels. ${ }^{3} \mathrm{He}$-based neutron detectors allow for higher detection efficiencies; however, at the expense of slow signal rise time characteristics and higher sensitivity to the gamma-ray backgrounds. It is therefore desirable to evaluate and develop technologies with potential to exceed performance parameters of standard fission chamber-based or ${ }^{3} \mathrm{He}$-based detection systems currently used in NDA instrumentation. The current work is focused on improving the capability to measure neutron emission from the different stages of the electrochemical process using boron-10 coated plate detectors with high speed amplifiers. Prototype detectors have been developed and tested in high gamma-ray fields, up to 795 $\mathrm{R} / \mathrm{hr}$ (see figure 9 ).

To support the 2020 milestone, field testing of the current units will need to be conducted in order to assess their effectiveness in common NDA and monitoring applications. Additionally, the environment within hot cells used for pyroprocessing usually contain inert gas, and have high gamma, neutron fields, as well as contamination and high temperatures. Testing of the current detectors in these environments and possible modification will need to be performed. 


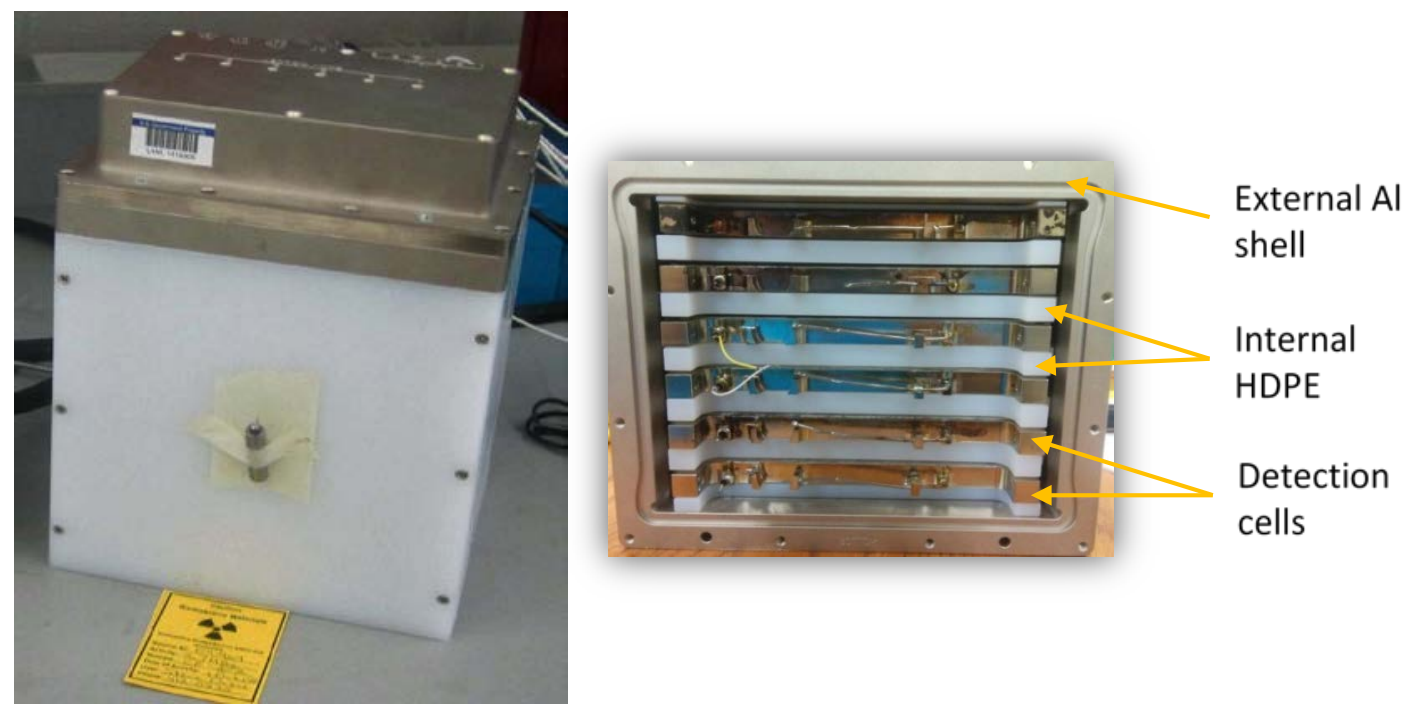

Figure 9. High dose neutron detector external (left) and internal (right)

\subsubsection{In Situ Measurement of Pu Content in U/TRU Ingot}

During normal operation of the ER, pure $U$ metal is deposited on the solid cathode while rare earth and actinide metals accumulate in the molten salt. After multiple fuel batches, a liquid cadmium cathode is used to co-deposit $\mathrm{U}, \mathrm{Pu}$, rare earths, and other minor actinides from the salt. The metallic product from the liquid cadmium cathode is primarily $\mathrm{U}$ and $\mathrm{Pu}$ and the other components do not significantly affect the melting temperature of the metal. The Pu ratio in the U/TRU product is an important parameter to measure for material accountability and process monitoring. Ideally this measurement needs to be done in-situ and in a timely manner. At INL, a method to measure the Pu content in the U/TRU metallic ingot using the Pu-U binary phase diagram and the ingot melting temperature is under investigation. The binary phase diagram for $\mathrm{Pu}$ and $\mathrm{U}$ is available in the literature and can be used to determine the Pu composition once the melting temperature of the ingot is known. The main objective of this work is to develop an insitu method for measuring the melting temperature of the ingot.

A common method for determining the melting temperature of a material is to monitor the material temperature through melting and solidification, as the melting temperature is reached, the heat of fusion causes a deflection in the temperature profile with time. An experiment in the EDL laboratory at INL was conducted in the glovebox to test this principle with $\mathrm{Al}$ and $\mathrm{Ag}$. In this system, the metals were placed in a furnace crucible containing thermocouples (one directly in the melt and another just outside it) and then the material was slowly cooled. Figure 10 shows the temperature profiles of the two thermocouples for the Ag test. A clear deflection in the temperature profile marks the melting temperature of $\mathrm{Ag}$ at $962^{\circ} \mathrm{C}$. 
MPACT Implementation Plan: Lab-Scale Demonstration of Advanced Safeguards and Security Systems

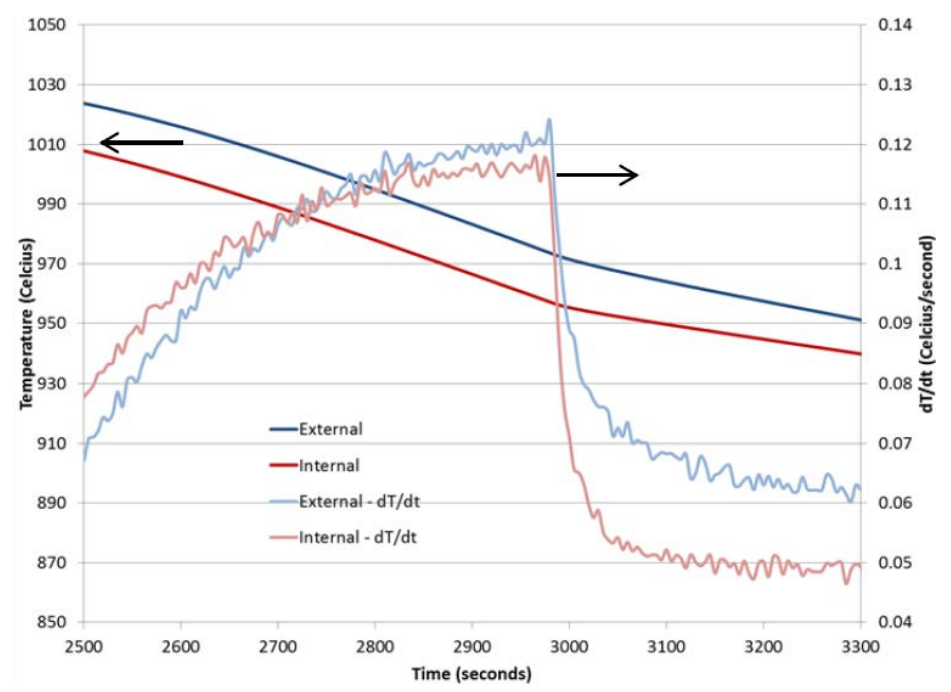

Fig. 10. Internal and external thermocouple readings as a function of time for the solidification of Ag (melting temperature of $962^{\circ} \mathrm{C}$ ).

The surrogate testing with $\mathrm{Ag}$ and $\mathrm{Al}$ has demonstrated the effectiveness of this method to measure the melting temperature of metals in a glovebox environment. The experimental setup is currently being modified for hot-cell operation so that a real U/TRU product can be tested using this approach as part of the JFCS. If this approach is successful in accurately determining the melting temperature of the U/TRU ingot, the amount of $\mathrm{Pu}$ in the ingot can be calculated (from the phase diagram) which greatly enhances material accountancy and process monitoring of $\mathrm{Pu}$ in pyroprocessing.

\subsubsection{MicroCalorimetry}

Detectors based on cryogenic microcalorimeter sensors have emerged as powerful tools for the detection of a variety of radiation types. These novel detectors are capable of photon and charged particle spectroscopy with extraordinary energy resolution. Microcalorimeters have been applied to a wide range of radiation measurements, from sub-keV X-ray measurements to $\alpha$-decay spectroscopy beyond $6 \mathrm{MeV}$. In the realm of $\gamma$-ray spectroscopy, microcalorimeter detectors have achieved energy resolutions with FWHM resolution as low as $22 \mathrm{eV}$ at $97.4 \mathrm{keV}$, more than an order of magnitude improvement in energy resolution over semiconductor detectors. In the realm of nuclear safeguards, a precise and accurate measurement of the intensity of $\gamma$-rays associated with the decay of various Pu isotopes is a vital ingredient in the determination of the relative Pu isotopic mass abundances. The improved resolution of microcalorimeters allow for extremely high precision measurements of complex $X$ - and $\gamma$-ray emissions. Rigorous uncertainty analysis has demonstrated the potential of microcalorimeter gamma spectroscopy to achieve significantly higher precision and accuracy for plutonium isotopic ratio measurements than existing NDA methods. Ultimately, use of this rapid, nondestructive measurement technology could reduce reliance on sampling, mass spectrometry and chemical analysis, thus enabling better constraints on diversion scenarios with limited resources.

With support from MPACT, LANL is developing microcalorimeter gamma spectrometers based on superconducting transition-edge sensors (TESs) consisting of a thin-film $\mathrm{Cu}$-Mo bilayer with a normalto-superconducting transition near $100 \mathrm{mK}$ (figure 11). In order to develop a useful sensor for safeguards applications, large arrays of these detectors have been manufactured for high detection efficiency and count rate capability. In coordination with a NEUP funded collaboration, a microwave readout system has 
been developed allowing high-bandwidth readout of large arrays of sensors. This new readout architecture is expected to enable microcalorimeter gamma spectrometers with detection efficiency and count rate capability surpassing that of planar high-purity germanium detectors in the near future.
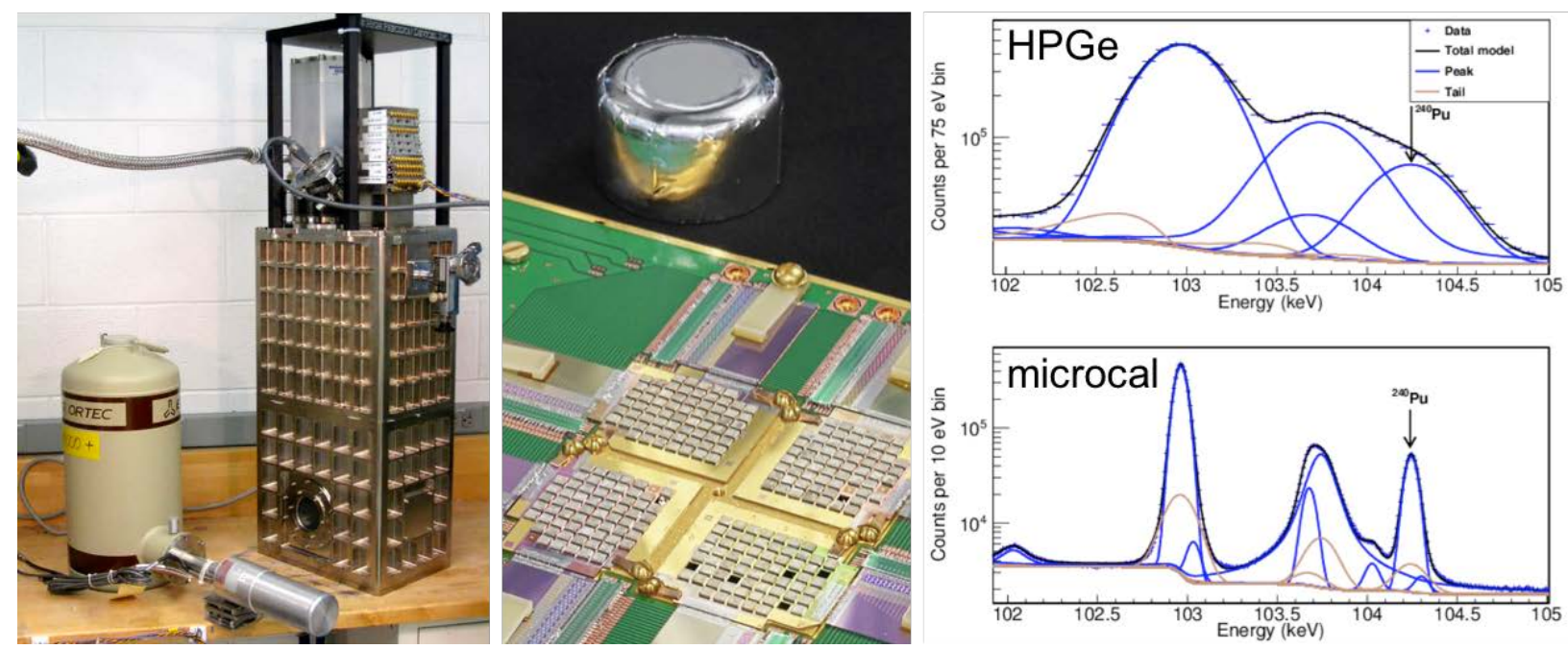

Figure 11: External view of microcalorimeter instrument, compared to a typical germanium detector. (Left) 256-pixel microcalorimeter gamma spectrometer, compared to a planar germanium detector crystal. (Center) Microcalorimeter and germanium spectra of Pu items in the complex $100-\mathrm{keV}$ region illustrate the advantage of improved energy resolution in resolving overlapping peaks like from the important $104.24 \mathrm{keV}{ }^{240} \mathrm{Pu}$

gamma ray. (Right)

To support the 2020 milestone, field demonstration of microcalorimetry to perform measurements of SNF and materials from pyroprocessing ideally should be performed to evaluate performance relative to common NDA and DA measurement systems. Extensive measurements of plutonium reference standards have already been performed using a 256-pixel array. A new instrument is currently in development, using the microwave readout architecture, which will enable count rates comparable to germanium detectors. This instrumentation development is a key component of advancing microcalorimeter gamma spectroscopy to become a practical analytical technique. This new instrument will be used for field testing at DOE facilities to demonstrate performance and gain operational experience with real materials. Field testing will focus on measurement of complex materials, including those with fission products and minor actinides, to quantitatively determine the achievable precision and accuracy of microcalorimeter gamma spectroscopy in an advanced fuel cycle facility.

\subsection{Facility Modelling}

\subsubsection{D Facility Modelling}

The Pyrochemical Facility Operations Model (PyFOM) is an operations model that simulates the physical location and dimensions of unit operations within a pyrochemical reprocessing facility. The code was developed using ExtendSim software (Imagine That, Inc.). Process timing and sequencing of material transfers, as well as the required mechanical movements of cranes, robots, etc., are used to optimize the placement of the equipment and thus to optimize the facility layout, and identify where redesign may be required. Dimensions and time requirements for the various operations within an electrochemical facility are input by the user. These parameters are typically derived from the output of the AMPYRE and DyER codes with translation by SMEs to actual equipment dimensions based on material properties and operating conditions. The output was used to develop a 3-dimensional layout of a conceptual $100 \mathrm{MT} / \mathrm{yr}$ 
facility (see figure 12). The code was used to better define the process flowsheet and equipment concepts. It also serves to identify process bottlenecks which led to improvements in processing and equipment designs.

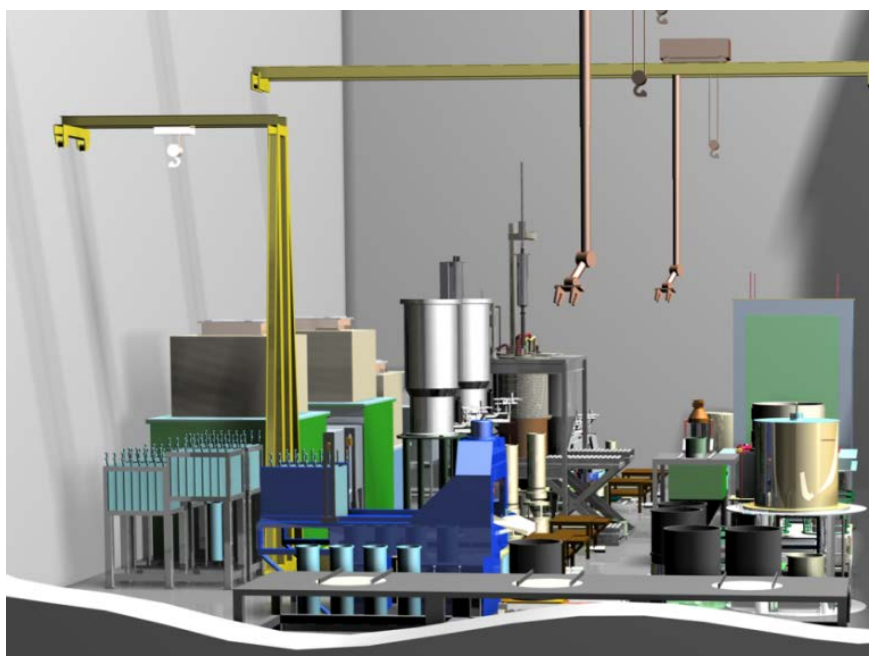

Figure 12. Conceptual 3D model of a $100 \mathrm{MT} / \mathrm{yr}$ pyroprocessing facility

There are several areas where the 3D facility modeling can integrate with other capabilities to support the 2020 milestone. The AMPYRE process flowsheet can be augmented and its output formatted to directly provide data required for the PyFOM, and similar facility codes. The radiation mapping work at LANL can use the 3D layout to improve the fidelity of the facility representation in those models. The mapping can then inform the selection, placement, and orientation of sensors and shielding. This may in turn result in additional refinement of the 3D layout, resulting in a reassessment using the SSPM. The STAGE security models (see section 2.5.1) also benefits from having a better 3D layout of an entire facility; similarly, security assessments may lead to revisions in facility layout. Because of these potential interfaces, the data transfer mechanisms and output file types should be explored.

\subsubsection{Radiation Mapping and Signatures}

Radiation maps are of interest because the quantification of burnup and fissile content for irradiated nuclear fuels is relevant to fuel reprocessing and safeguards applications. A range of LWR and metal fuels were simulated as input to oxide reduction and electrorefining using MCNP6. One key finding from this work is that MCNP6 can be used to develop neutron and gamma radiation maps for material that is dispersed throughout a pyroprocessing facility. Pronounced differences are evident for many of the oxide and metal fuel delayed neutron (DN) and delayed gamma (DG) radiation signatures. Neutron and radiation profiles exhibit sensitivities to many factors, including the type of ER, electrorefining state, fuel burnup and cooling time, initial ${ }^{235} \mathrm{U}$ enrichment, and plutonium content. The presence of these sensitivities suggests the possibility of exploiting measured DN and DG radiation for the purpose of inferring quantities such as ${ }^{235} \mathrm{U}$ enrichment and plutonium content. Another key finding is that the MCNPX v270 can used to simulate material motion and the associated radiation signatures in a pyroprocessing facility. Several modifications to MCNPX and MCNP6 were made to allow simulating detector response to time-varying radiation fields.

To meet the 2020 milestone, the radiation mapping and signature activities will be needed to develop realistic radiation signatures for the virtual electrochemical facility to enable assessment of qualitative and quantitative NDA systems, as well as radiation based process monitoring technologies. 


\subsection{Security Modelling}

Security modeling is based on evaluating the site response to a defined threat. This includes the response of the assets to theft and acts of radiological sabotage. There are three different types of modeling that are used. Force-on-force modeling examines the effectiveness of various guard force and installation security configurations against adversary threats. Consequence modeling seeks to determine the radiological result of a successful sabotage event. Risk-based scoring represents an attempt to assign a difficulty metric to each attack scenario against an assumed physical protection system for a given site.

Security modeling is often conducted in independent, parallel evaluations. Integration of the different types of modeling serves to provide a more complete security assessment and allow for site optimization as shown in figure 13. The level of integration between current modeling thrusts remains minimal. As modeling progresses in the future, integration is expected to increase, especially as economics are considered more prominently among the figures of merit (FOM's).

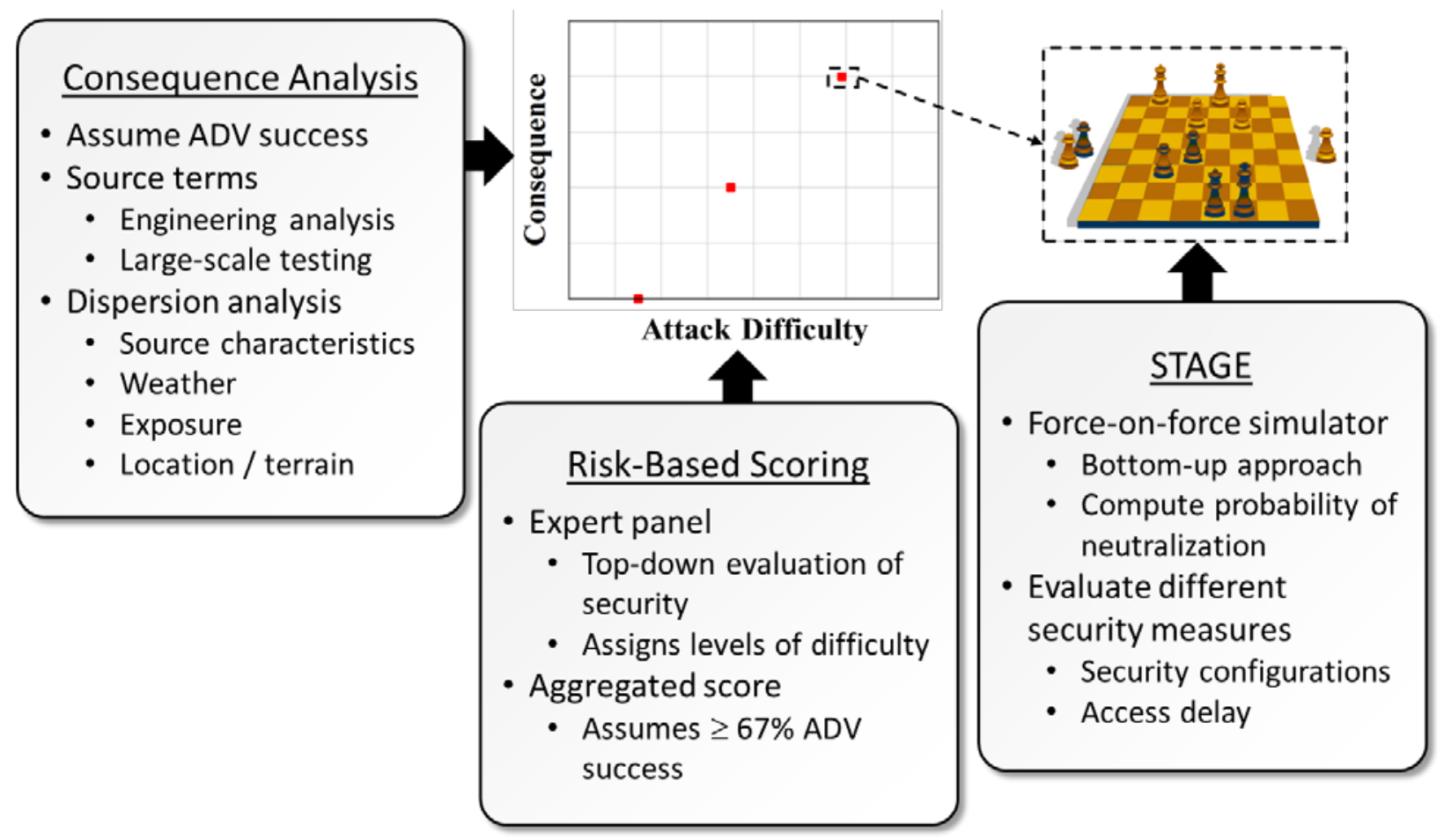

Figure 13: Site security optimization based on the integration of multiple modeling efforts.

The modeling inputs for the various tools include the design basis threat (DBT) and the site characteristics. The DBT includes the number of adversaries, allowable weapons, special tools and equipment, tactics, and level of determination. The site characteristics include source material, containment design (including release path), access delay features, entry control points, vehicle barriers, building layout, number of guards, weapons, mobility, training, and tactics.

\subsubsection{STAGE Force-on-Force Modeling}

A number of tools exist for physical security analysis and design. One of the more current capabilities is the STAGE (Scenario Toolkit and Generation Environment) commercial modelling and simulation 
software. This software has been applied for a variety of security applications, particularly for force-onforce combat engagements for outside adversary attacks at Sandia National Laboratories.

STAGE has also been used to model insider diversion scenarios. One key advantage of STAGE is the ability to fully model a 3D environment, which means that specific safeguards and security scenarios can be modeled. Figure 14 shows both a 3D facility model and a bird's eye view of a facility using STAGE. STAGE contains a library of typical physical security elements (for example sensors, portal monitors, guard forces, etc.) It provides the following capabilities:

- Logic based behavior: Human entities model the ability to "make a decision" based on the current situations and partially controlled by probability analysis.

- Ground navigation: Humans and mobile equipment can dynamically find paths both inside and outside the facility. Sensing abilities possessed by the human entities enable visual detection of other humans and objects.

- Event-based entity missions: Help define the main thread and strategies of the scenarios.

- $\quad$ Scripting support: Provides the ability to integrate data from other codes.

- 2D/3D environment: Provides visual representation of the scenarios.

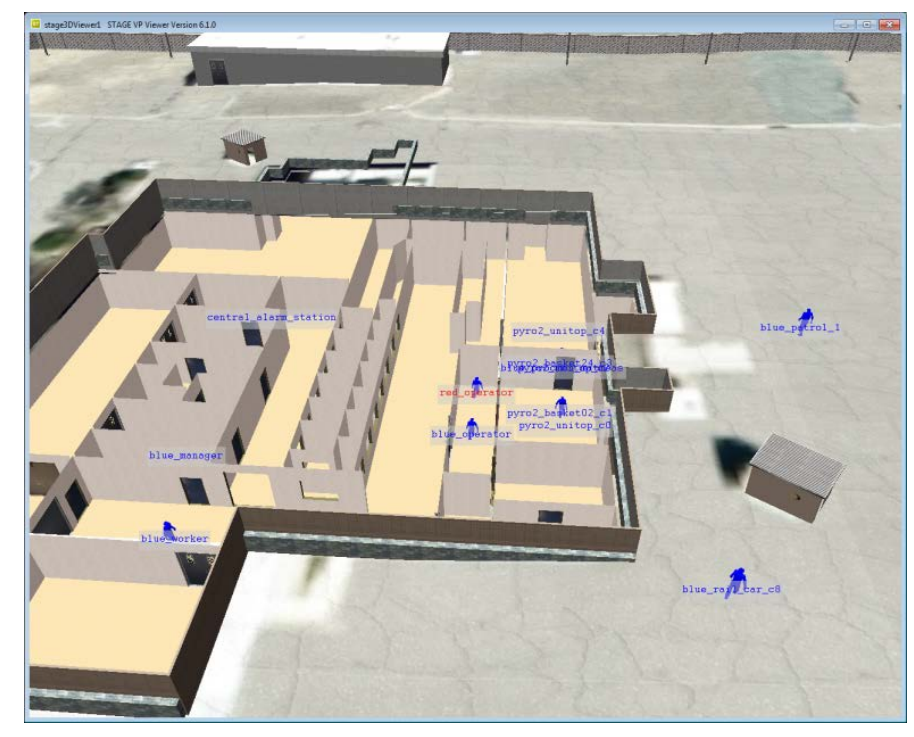

Figure 14. Example STAGE model

Past work has integrated the SSPM and STAGE tools for insider diversion scenario analysis. The SSPM was used to generate probability of detection curves that were fed into STAGE to improve the security analysis. Future work can also consider how the 3D facility models can be better integrated with the STAGE model.

\subsubsection{Consequence Modelling}

Consequence modelling is focused on defining the source term from successful attack scenarios based on information about the facility and the adversary toolset and tactics from the design basis threat (DBT). The amount of the source term released, or the release fraction (RF), is determined using information from various integrated, large-scale and separate effects testing, in addition to shock physics modelling. These source terms are then inputted into dispersion codes to calculate different FOM's such as dose, land contamination, or estimated economic impact. 
MPACT Implementation Plan: Lab-Scale Demonstration of Advanced Safeguards and Security Systems

Simple, generic dispersion analyses may be conducted with HotSpot. Site specific analyses with details of terrain and local, time-dependent weather files require more complex simulation packages such as MELCOR Accident Consequence Code Systems (MACCS) or the suite of models developed by the National Atmospheric Release Advisory Center (NARAC).

Past work has focused on consequence modelling of wet and dry storage, but this could be extended to pyroprocessing facilities to support meeting the 2020 milestone. Pyroprocessing will produce a variety of products and waste forms that might be considered as sabotage targets. In general, the plant designs are robust from a physical security perspective, but specific source terms should be analyzed. The systems level models can generate the source term data, but the work will need to be targeted to examine scenarios that could be realistic from a physical protection standpoint.

\subsubsection{Risk-Based Scoring}

A third type of security modelling seeks to grade threats or vulnerabilities by incorporating the degree of difficulty and physical security performance into a risk-based prioritization scheme. The risk-informed management of enterprise security (RIMES) is one such method that surveys an expert panel to determine an aggregated metric for an adversary to successfully execute an attack against a site. This metric is assumed to be comparable to the relative difficulty of the attack scenario. By comparing the RIMES score with the consequence, potential deficiencies in the protection performance can be readily identified and corrected. One of the key points of the difficulty scoring is to examine scoring across an entire fuel cycle so that security investments are appropriate and normalized for various facilities. For example, it makes little sense to add additional security at nuclear reactors if another facility type is much more vulnerable to theft or sabotage.

\section{Applications to Advanced Fuel Cycles}

The Implementation Plan is focused on safeguards and security by design for electrochemical reprocessing plants. This focus was chosen in part because of the relevancy and safeguards challenges of pyroprocessing. However, many of the MPACT capabilities were originally developed to support aqueous reprocessing, and the distributed virtual test bed approach has applicability to a range of advanced fuel cycles. Future MPACT activities will necessarily need to consider different areas of the fuel cycle. Much of the work in MPACT over the past decade has focused on reprocessing with some targeted work on used fuel storage. The MPACT capabilities can be applied to other facility types.

\subsection{Aqueous Processing}

Referring back to Figure 1 on the Virtual Facility Distributed Test Bed concept, the overall concept would not change with aqueous. The flowsheet model would be AMUSE, the safeguards model is a different version of the SSPM, the 3D facility modelling approach would not change, and the physical security modelling would still use STAGE. These four core capabilities still interact in the same manner. The higher fidelity models, instrumentation technologies, and test beds would change. Past work has developed unit operation models for aqueous plants. There is a vast amount of past work on measurement instrumentation for aqueous plants. Test beds would be different and could include the past work at HCanyon for example. Again, the interplay between the capabilities would be the same, and similar integration efforts have been developed in the past.

The ANL AMUSE code, a predecessor to AMPYRE (section 2.1.1), is used to design process flow sheets based on solvent extraction. The code includes thermodynamic data for a number of elements and 
MPACT Implementation Plan: Lab-Scale Demonstration of Advanced Safeguards and Security Systems

polyatomic species common to spent nuclear fuel processing. The code calculates steady state process flowsheets for PUREX, UREX, TRUEX and other flowsheets for user-supplied design parameters, and can calculate additional system if distribution coefficients data are available. A time-dependent version of the code, dyAMUSE, has also been developed to simulate the start-up, shutdown, and transient response of process flowsheets to changes in operations.

The Co-Decontamination Demonstration project (CoDCon) at PNNL is a novel approach for an aqueous co-extraction processing stream of $\mathrm{U}$ and $\mathrm{Pu}$ where $\mathrm{Pu}$ is never isolated in any separation steps. The concept leverages in-line process monitoring techniques to ensure that the $\mathrm{Pu} / \mathrm{U}$ ratio is maintained at a specific threshold and that no purified Pu stream can be isolated or diverted at any point in the process. Some of the existing MPACT modelling capabilities, including AMUSE and the SSPM, are being used to support the project, and additional NDA and external processing monitoring capabilities could be leveraged by this campaign to further enhance and support this effort. Future work may consider how the CoDCon reprocessing demonstration platform at PNNL could be leveraged to support the 2020 milestone.

Testing and deployment of the Multi-Isotope Process monitor (MIP) at the H-Canyon nuclear separations facility of SRNL has successfully been executed with support from the MPACT campaign. This effort coupled robust process monitoring techniques that are both nondestructive and non-invasive in application (i.e. the detectors can be deployed external to the reprocessing system) with multivariate analyses Principal Component Analysis (PCA) and K-means clustering algorithms to successfully identify both major and minor variations within the operations of a nuclear separations facility. Similar systems could be rapidly deployed and leveraged to support both the CoDCon effort and to provide additional benchmark, validation and verification data for the 2020 milestone.

$\mathrm{H}$-Canyon is building a positive reputation for supporting the testing of process monitoring technologies at its facility that can demonstrate novel and advanced approaches for safeguarding current and advanced aqueous processes. The MIP monitor effort helped develop a robust and foundational pathway for other safeguards projects, techniques, capabilities, and programs to be deployed within the facility and in a "real world" environment. Since H-Canyon leveraged successes from similar decommissioned facilities on the Hanford site, this facility is unique with its capability of redirecting virtually any material in a variety of pathways within its process. As MPACT moves beyond the 2020 milestone this capability could be leveraged to support multiple process monitoring platforms and with additional funding $\mathrm{H}-$ Canyon could modify its system to help support targets of interest within the safeguards program.

The INL also has an unshielded, skid-based reprocessing plant based on the PUREX flowsheet for testing and demonstration. Within the next year, depleted uranium will be processed with the system. Many nonradiation based technologies could be tested to provide data from a complete processing operation.

\subsection{Advanced Reactors}

Advanced reactors with unique fuel types are gaining interest domestically and internationally, and present unique safeguards challenges. Liquid fueled reactors in particular have a number of safeguards challenges. Typical light water reactors have few safeguards challenges because materials accountancy is focused mainly on item accounting of assemblies. Liquid fuels with the potential for on-line reprocessing add materials accountancy complexity and diversity of diversion scenarios. It would be relevant and timely to develop the MPACT capabilities to support research on molten salt and other advanced reactors. 
MPACT Implementation Plan: Lab-Scale Demonstration of Advanced Safeguards and Security Systems

\subsubsection{Molten Salt Reactors}

New safeguards needs and verification challenges have arisen due to the growth in the number of MSR design variants. For example, startups in the USA have not only expanded on the original ORNL MSR Experiment (MSRE) design, but have developed options to consider using spent nuclear fuel (SNF), uranium-plutonium, transuranics, fast spectrum designs, as well as the original thorium-based concepts. European MSR developments (namely, Moltex and Seaborg) focus on burning SNF. Similarly, under the Generation IV International Forum (GIF) FS-MSR developments have been advancing, such as the Russian Molten Salt Actinide Recycler and Transmuter (MOSART) that would have the capability to burn transuranic (TRU) waste from spent uranium oxide (UOX) and mixed oxide (MOX) light water reactor (LWR) fuel. China has several approaches underway, including a 235U/Th-based pebble bed solid-fuel MSR (FHR) and a liquid-fuel MSR similar to the MSRE/MSBR designs of ORNL. Some of the domestic and international designs will utilize on-site, on-line reprocessing (separation of fissile material from salt, or only fission product removal) while others will use an off-site facility either for long-term storage or reprocessing.

While much uncertainty on the final design of MSR remains, several of the technologies MPACT has developed or would utilize for an advanced pyroprocessing safeguards system would be applicable to these MSR designs, and the efforts to integrate facility and process models with quantitative and qualitative operational data would be directly applicable. MPACT will work closely with DOE-NE MSR efforts to leverage existing MPACT technologies, and help identify and assess new technologies.

\subsubsection{Small Modular Reactors}

Small modular reactors (SMRs) offer unique advantages in many remote applications due to their small size and modularity. Similar to MSRs, several designs have been proposed and are in various stages of $\mathrm{R} / \mathrm{D}$ and demonstration. Unique safeguards challenges exist for several of these designs due to online reloading and non-uniquely identifiable fuel assemblies. Some of the MPACT developed technologies may be directly applicable to SMRs, efforts to integrate facility and process models with quantitative and qualitative operational data would likely be directly applicable.

\subsection{Advanced Fuel Fabrication}

Fuel fabrication has not been an area of MPACT focus in the recent past, but contains many elements that are similar to reprocessing plants. The four core systems level models could be modified to create fuel fabrication versions. Fuel fabrication after pyroprocessing may be the most relevant case, as well as fuel for molten salt reactors and fast reactors. Additive manufacturing and other advanced manufacturing approaches that do not rely on upon traditional manufacturing methods could also be considered.

\section{Gaps and Needed Technologies}

The Advanced Integration Roadmap [2] identifies several technological gaps, as well as the related status and path forward of activities needed to allow realization the next generation of nuclear material management. These are summarized in the Table 1. Specific technological gaps for the advanced fuel cycle and reactor considered in this plan summarized in Tables 2 and 3 . This listing is not meant to be exhaustive, but instead to focus activities towards meeting the 2020 milestone. 
MPACT Implementation Plan: Lab-Scale Demonstration of Advanced Safeguards and Security Systems

Table 1. Identified technology gaps for advanced integration and analysis

\begin{tabular}{|c|c|c|c|}
\hline \multicolumn{4}{|c|}{ Advanced Integration } \\
\hline Gap & Relevance & Path Forward & Current status \\
\hline Uncertainty quantification & $\begin{array}{l}\text { System performance } \\
\text { assessment }\end{array}$ & $\begin{array}{l}\text { Build on current work and develop } \\
\text { new tools/methods }\end{array}$ & $\begin{array}{l}\text { Method for generating ROC curves } \\
\text { based on simulated data to obtain } \\
\text { Probability of Detection for a given } \\
\text { sensor. }\end{array}$ \\
\hline Correlation analysis & $\begin{array}{l}\text { Reduces or increases } \\
\text { overall uncertainty }\end{array}$ & $\begin{array}{l}\text { Tools and methods for discovery are } \\
\text { needed }\end{array}$ & $\begin{array}{l}\text { Bayesian Fusion method for combining } \\
\text { probabilities of detection of multiple } \\
\text { sensors. }\end{array}$ \\
\hline Process monitoring & Augmentation of NMA & $\begin{array}{l}\text { List of PM technologies are needed } \\
\text { for specific fuel cycle technologies }\end{array}$ & $\begin{array}{l}\text { NEUP to look at PM technologies for } \\
\text { pyroprocessing. PM optimization and } \\
\text { effectiveness analysis performed for } \\
\text { pyroprocessing and aqueous processes. }\end{array}$ \\
\hline $\begin{array}{l}\text { Advanced nuclear material } \\
\text { accountancy }\end{array}$ & $\begin{array}{l}\text { Push limits within } \\
\text { traditional NMA } \\
\text { architecture }\end{array}$ & $\begin{array}{l}\text { Emerging technologies being } \\
\text { developed (e.g., microcal) }\end{array}$ & MPACT R\&D efforts are ongoing. \\
\hline Facility layout & $\begin{array}{l}\text { Safeguards and security } \\
\text { by design - rapid } \\
\text { evaluation }\end{array}$ & $\begin{array}{l}\text { Build on current models, modular } \\
\text { capability for specific applications }\end{array}$ & MPACT R\&D efforts are ongoing. \\
\hline $\begin{array}{l}\text { Advanced information } \\
\text { technology/control systems }\end{array}$ & $\begin{array}{c}\text { Automation leads to } \\
\text { enhanced access to large } \\
\text { data streams such as } \\
\text { state-of-health } \\
\end{array}$ & $\begin{array}{l}\text { Identify and demonstrate promising } \\
\text { technologies in context of regulatory } \\
\text { environment }\end{array}$ & $\begin{array}{l}\text { The input and output from several } \\
\text { MPACT technologies is being analyzed } \\
\text { for ways of feeding into one another. }\end{array}$ \\
\hline Diversion analysis & $\begin{array}{l}\text { Advanced fuel cycles } \\
\text { need assessment }\end{array}$ & $\begin{array}{c}\text { Develop priority facility list and } \\
\text { identify areas where new tools are } \\
\text { needed }\end{array}$ & $\begin{array}{l}\text { Demonstrated in the past for both } \\
\text { aqueous and echem reprocessing. }\end{array}$ \\
\hline Cost-benefit analysis & $\begin{array}{l}\text { Optimization of overall } \\
\text { system }\end{array}$ & $\begin{array}{c}\text { Develop priority technology list, } \\
\text { overlay regulatory requirements and } \\
\text { gaps, identify emerging needs for } \\
\text { tools } \\
\end{array}$ & $\begin{array}{l}\text { Advanced Integration Methodology } \\
\text { will provide ways of measuring this. }\end{array}$ \\
\hline \multicolumn{4}{|c|}{ Table 2. Identified technology gaps for electrochemical processing } \\
\hline \multicolumn{4}{|c|}{ ctrochemical Processing } \\
\hline Gap & Relevance & Path Forward & Current status \\
\hline Input Accountancy & $\begin{array}{l}\text { Primary accountancy } \\
\text { input }\end{array}$ & $\begin{array}{l}\text { In coordination with DOE NNSA, test } \\
\text { methods in JFCS and assess SNF } \\
\text { NDA campaign applicability }\end{array}$ & $\begin{array}{l}\text { SNF NDA campaign completed; JFCS } \\
\text { testing of representative sampling } \\
\text { planned }\end{array}$ \\
\hline Oxide Reduction Monitoring & $\begin{array}{l}\text { Potential diversion } \\
\text { pathway }\end{array}$ & $\begin{array}{l}\text { Development and testing of } \\
\text { quantitative and qualitative } \\
\text { monitoring technologies }\end{array}$ & $\begin{array}{l}\text { MPACT R\&D of voltammetry probe } \\
\text { for qualitative identification ongoing; } \\
\text { application of bubbler to OR planned }\end{array}$ \\
\hline $\begin{array}{l}\text { Electrorefining monitoring } \\
\text { and accountancy }\end{array}$ & $\begin{array}{c}\text { Primary in-process SNM } \\
\text { location }\end{array}$ & $\begin{array}{c}\text { Development and testing of } \\
\text { quantitative and qualitative } \\
\text { monitoring technologies and improved } \\
\text { accountancy measures } \\
\end{array}$ & $\begin{array}{c}\text { MPACT R\&D of automated sampler, } \\
\text { actinide sensor, voltammetry, bubbler } \\
\text { ongoing }\end{array}$ \\
\hline $\begin{array}{l}\text { U/TRU and U product } \\
\text { monitoring and acccountancy }\end{array}$ & Process output products & $\begin{array}{c}\text { Development and testing of } \\
\text { quantitative and qualitative } \\
\text { monitoring technologies and improved } \\
\text { accountancy measures }\end{array}$ & $\begin{array}{l}\text { MPACT R\&D of thermocouple, high } \\
\text { dose neutron detector and } \\
\text { microcalorimeter ongoing }\end{array}$ \\
\hline Waste monitoring & $\begin{array}{l}\text { Potential diversion } \\
\text { pathway }\end{array}$ & $\begin{array}{l}\text { Development and testing of } \\
\text { quantitative and qualitative } \\
\text { monitoring technologies }\end{array}$ & $\begin{array}{l}\text { MPACT R\&D of high dose neutron } \\
\text { detector ongoing }\end{array}$ \\
\hline Security & $\begin{array}{c}\text { Security and } \\
\text { Consequence Analysis }\end{array}$ & $\begin{array}{l}\text { Develop a full STAGE model and } \\
\text { evaluate theft and sabotage targets for } \\
\text { pyroprocessing }\end{array}$ & $\begin{array}{l}\text { STAGE model and analysis has not } \\
\text { been applied to pyroprocessing facility }\end{array}$ \\
\hline
\end{tabular}


MPACT Implementation Plan: Lab-Scale Demonstration of Advanced Safeguards and Security Systems

Table 3. Identified technology gaps for aqueous processing, advanced reactors and fuel fabrication

\begin{tabular}{|c|c|c|c|}
\hline \multicolumn{2}{|c|}{ Aqueous Processing, Advanced Reactors and Fuel Fabrication } \\
\hline Relevance & \multicolumn{2}{|c|}{ Path Forward } & Current status \\
\hline Aqueous Process Monitoring & $\begin{array}{c}\text { Quantitative monitoring } \\
\text { for off-normal operation }\end{array}$ & $\begin{array}{c}\text { Development and testing of } \\
\text { quantitative and qualitative } \\
\text { monitoring technologies }\end{array}$ & $\begin{array}{c}\text { MPACT R\&D of MIP monitor and } \\
\text { testing at H-Canyon; planned additional } \\
\text { testing at SRNL, PNNL and INL. }\end{array}$ \\
\hline Accountancy and monitoring & $\begin{array}{c}\text { Unique and challenging } \\
\text { accountancy and } \\
\text { monitoring }\end{array}$ & $\begin{array}{c}\text { Identify and test technologies } \\
\text { developed for pyroprocessing that are } \\
\text { applicable, and identify remaining } \\
\text { gaps }\end{array}$ & No MPACT activities \\
\hline Advanced fuel manufacturing & $\begin{array}{c}\text { Unique fuel materials } \\
\text { and processes require } \\
\text { modification of existing } \\
\text { strategies }\end{array}$ & $\begin{array}{c}\text { Identify and test existing technologies } \\
\text { and approaches that are applicable, } \\
\text { and identify remaining gaps }\end{array}$ & No MPACT activities \\
\hline
\end{tabular}

Consideration has been given to expanding the modelling efforts to develop a more integrated model that includes multiple capabilities. Upon discussion, though, there seem to be more disadvantages and little compelling reason to move in that direction. One of the key issues is that safeguards and security analyses need to be performed by subject matter experts, and these analyses are much more effective if those experts can use their own tools and capabilities. Integrating all capabilities into a master code could weaken the individual analyses. This is one of the drivers for linking the codes and capabilities rather than integrating everything. As has been described, there are some capabilities that can be integrated into models, but many of the integrations are less direct.

\section{Conclusions}

This implementation plan summarizes the activities under the MPACT campaign that are needed to allow for lab scale demonstration of an advanced safeguards and security system in the 2020 timeframe. The 2020 milestone will include an analysis of the effectiveness of advanced safeguard and security technologies applied to electrochemical processing, and comparison to traditional accountancy and security approaches. Key metrics for safeguards such as standard error of inventory difference, probability of detection and timeliness will be considered, as well as security factors such as probably of theft/sabotage success, timeliness and consequence analysis. While focus is on demonstrating technologies for electrochemical processing, other advanced fuel cycles, reactors and fuel fabrication may also be addressed as funding and Nuclear Technology R\&D program priorities dictate. 
MPACT Implementation Plan: Lab-Scale Demonstration of Advanced Safeguards and Security Systems

\section{References}

1. Cipiti, B., Dunn, T., Durbin, S., Durkee, J., England, J., Jones, R., Ketusky, E., Li, S., Lindgren, E., Meier, D., Miller, M., Osburn, L., Pereira, C., Rauch, E., Scaglione, J., Scherer, C., Sprinkle, J., and Yoo, T. (2016). "Material Protection, Accounting, and Control Technologies (MPACT) Modelling and Simulation Roadmap,” LA-UR-16-26045. Los Alamos, NM: Los Alamos National Laboratory.

2. $\quad$ Cipiti, B., Demuth, S., Durkee, J., Fallgren, Fugate, M., Hamada, M., Jarman, K., Key, B., Li, S., Meier, D., Miller, M., Osburn, L., Pereira, C., Rauch, E., Ticknor, L., Rao, D., and Yoo, T. (2016). "Material Protection, Accounting, and Control Technologies (MPACT) Advanced Integration Roadmap,” LA-UR-16-27364. Los Alamos, NM: Los Alamos National Laboratory. 